\title{
Estimating the Effects of Public Training on Polish Unemployment by Way of the Augmented Matching Function Approach
}

\author{
by \\ Patrick A. Puhani* \\ Centre for European Economic Research (ZEW), Mannheim
}

June 1999

Dr. Patrick A. Puhani

ZEW

L7, 1

D-68161 Mannheim

Germany

Tel.: +49621 1235-281

Fax: +49621 1235-225

e-mail: puhani@zew.de

JEL classification: E24, J64

Key words: training, evaluation, augmented matching function

*The author is also a Research Affiliate at the Center for Economic Policy Research (CEPR), London, UK, the Institute for the Study of Labor (IZA), Bonn, Germany, and a Research Fellow of The William Davidson Institute at the University of Michigan Business School, Ann Arbor, MI, U.S.A. 


\section{Non-technical Summary}

We analyse Polish active labour market policy (ALMP) training programmes from a macroeconomic (regional) point of view. The empirical evidence gives some tentative support to the view that public training programmes can be used to reduce unemployment. In the specifications where significant effects of training programmes can be detected, the average cost to reduce unemployment by one person in Poland through training programmes lies between $€ 200$ and $€ 500$. These costs are comparatively low in relation to the estimates for the Czech and Slovak Republic (between $€ 1,000$ and $€ 3,000$ ). Our regional analysis shows that the costs to reduce unemployment through training are higher in the industrial voivodships (between $€ 500$ and $€ 900$ ), than in the agricultural ones (around $€ 100$ ). No effects of training could be detected in the modern voivodships.

It has to be stressed that positive training effects can only be found when using register data. All model specifications that use Polish Labour Force Survey (PLFS) data suggest that training has no effect on the outflows from unemployment. One explanation of the sensitivity of the estimates with respect to the data set can be the imprecision with which outflows from unemployment are measured in some voivodships in the PLFS. Another explanation can be the different definitions of unemployment in the two data sets. The register unemployment data may include less long-term unemployed people than the PLFS data, because they might drop off the register after unemployment benefits run out. Our estimates of the coefficients on the unemployment stock in the matching functions are consistent with this hypothesis, which leads to the conclusion that training works better for the more able amongst the unemployed (as positive training effects are only found with the register data). This is unsurprising as training requires the ability to acquire new knowledge.

To test whether ALMP programmes have any displacement effects, or whether they can prevent unemployment to occur in the first place, the effects of the programmes on the outflows from employment into unemployment are estimated. We find no convincing evidence on displacement effects. However, start-up loans seem to be able to keep down the number of people who join the dole queue. Nevertheless, those people who dare to take out a loan in order to run their own business are only a small group and so the small costs estimated to keep a person in employment through start-up loans (between $€ 100$ and $€ 130$ ) should not be interpreted as safe evidence that an expansion of start-up loans would be successful. In addition, more empirical evidence would be required on start-up loans, especially on the type and length of self-employment, before any firm statements should be made. 


\begin{abstract}
We analyse Polish active labour market policy (ALMP) training programmes from a macroeconomic (regional) point of view. The effects of training programmes on the outflows from unemployment and the effects of all ALMP programmes on the outflows from employment (to identify displacement effects) are estimated. The variety of specifications presented is revealing. In contrast to other studies on Poland, we show that it can make a difference to the estimates whether current ALMP expenditure is excluded from the set of regressors to reduce the endogeneity problem, whether lagged dependent variables are included to take account of the dynamics, and whether fixed or random effects models are estimated.

The empirical evidence gives some tentative support to the view that public training programmes can be used to reduce unemployment.
\end{abstract}

\title{
Acknowledgement
}

This research was undertaken with support from the European Commission's Phare ACE Programme 1995 under the project 'Labour Market Policies, Income Support, and Work Incentives in Transition Economies'. I am grateful to my Ph.D. supervisor Klaus F. Zimmermann, IZA, Bonn, and University of Bonn, my colleagues Viktor Steiner, Herbert S. Buscher, and Florian Kraus, as well as Eugeniusz Kwiatkowski and Leszek Kucharski, University of Lodz, for many helpful comments. Many thanks go to Jan Witkowski, Central Statistical Office (GUS) and Warsaw School of Economics, without whom this research would not have been possible, for cooperation and advice within this project. I received excellent research assistance from Anja Triebe. All remaining errors are my own. 


\section{Introduction}

Double-digit unemployment rates have made the central and eastern European transition economies, including Poland, engage in active labour market policies. Programmes included training, subsidised jobs (called intervention works in Poland) and direct job creation (public works) as well as loan schemes (e.g. for selfemployment). As these programmes together swallow up about a third percent of GDP in Poland (Franz, 1995), they should be evaluated as to whether they fulfill one of their major objective, namely to decrease unemployment.

Emprical evaluations of active labour market programmes (ALMPs) in central and eastern Europe have taken two major approaches in the professional literature: microeconometric and macroeconometric. Whereas microeconometric studies estimate the impact of a programme on the individual's re-employment chances or earnings, the advantages of macroeconometric studies are that they are capable of capturing externalities by looking at aggregate data.

This paper takes the macroeconometric approach to ALMP evaluation for Poland using the augmented matching function as the basic modelling concept. ALMPs may not only have an effect on the participants themselves, but may very well have effects on the non-participant unemployment population or even the employment population. In Haskel and Jackman's (1988) terminology, substitution effects occur when the subsidised activity would have occurred even without the subsidy, but instead of employing an unemployed worker without subsidy, the employer now takes on somebody who receives a subsidy from the labour office. If substitution effects are prevalent, ALMPs do not increase the total outflows from unemployment into employment, but merely alter the composition of the outflows.

Furthermore, macroeconomic data can also identify displacement effects. Displacement effects occur when the hiring of a subsidised worker leads to a firing of a non-subsidised worker. With displacement effects, ALMPs may not lower unemployment in the economy as a whole, yet they benefit the participants and increase the turnover of the unemployment pool. Given the stagnancy of the unemployment pool in Poland, it has been argued that merely increasing its turnover would be a positive achievement for equity reasons (Boeri, 1996). In this paper, we will also test for the existence of displacement effects by estimating the dependence of the outflows from employment into unemployment on expenditures on active labour market policies. If displacement effects predominate, there should be both a positive effect of ALMPs on the outflows from unemployment into employment and on the outflows from employment into unemployment.

Of course, ALMPs may have no effects on the labour market at all. In this case, they just constitute a deadweight loss through the waste of taxpayers' money. If 
deadweight effects prevail, both macro- and microeconometric studies would estimate the effects of ALMPs on employment to be zero.

The paper is structured as follows. In section 2, we will introduce the concept of the augmented matching function. A summary of empirical studies using augmented matching functions is provided in Section 3. The data and variables which we use for the empirical study are presented in Section 4. Section 5 discusses some econometric issues. The estimation results are displayed and discussed in Section 6, followed by the conclusions in Section 7.

\section{The (Augmented) Matching Function Approach}

New work contracts (matches) are the outcome of a complex search process, in which workers look for adequate jobs and firms look for adequate workers. The matching function is a macroeconomic concept which aims to summarise the outcome of this complex reality. This is done by relating hirings of workers to a minimum set of determining variables. The basic tenet of the matching function is to model matches of unemployed workers with vacancies as outcomes of a production process which has stocks of unemployed and vacancies as its main inputs (Blanchard and Diamond, 1989; 1990; Pissarides, 1990). Pissarides (1990) develops a macroeconomic model of equilibrium unemployment with the matching function as a main ingredient to it. In Pissarides' (1990, Chapter 4) model, constant returns to scale in the matching function are assumed to ensure the uniqueness of equilibrium. This simplification may seem rather arbitrary. However, there is empirical evidence for the existence of a constant returns to scale matching function of a Cobb-Douglas form for many economies. The matching function has thus become an attractive tool for analysing labour market flows empirically.

The microeconomic foundation of the matching function is that both workers and firms have to search for their appropriate match in a world of uncertainty. The inclusion of uncertainty is an extension to the standard neoclassical model where all information in the economy permeates instantaneously through to all agents. With uncertainty and transaction costs, a worker will receive a number of job offers in a specific interval which is drawn from some known or unknown distribution. He or she then has to decide whether to accept that offer or wait for a better one to arrive. Similarly, a firm with a vacancy will receive a number of job applications and has to decide whether to employ somebody of the applicants or whether to leave the vacancy open and wait for a more qualified worker to apply for the job. Clearly, the more unemployed people and vacancies there are in the economy, the more contacts will be established between workers and vacancies. As a consequence, the expected number of matches (hirings) will increase. Constant returns to scale in the matching function means that if the labour market were twice as large in terms of unemployed people and vacancies, the number of matches would be twice as large, too. Increasing or decreasing returns to matching, on the other hand, would mean that 
there are positive or negative externalities with respect to the size of the labour market, which increase or decrease the matching efficiency, respectively.

A weakness of the matching function concept is that it does not consider job-to-job transitions. The assumption is that vacancies are filled only with unemployed people. However, there is some evidence for Hungary and the Czech and Slovak Republics that many workers move from the public to the private sector without any intervening unemployment spell (Boeri, 1994a; 1994b), which is also very common in western countries ( $c f$. Franz, 1996, Chapter 6, on western Germany). This also seems plausible for Poland. Yet as data on job-to-job transitions are generally not available, previous empirical implementations of the matching function had to put up with ignoring this phenomenon. Although this is somewhat unsatisfactory, econometric estimates of the matching function will still be unbiased as long as the number of the employed persons searching for a job is proportional to the number of unemployed persons searching for a job. So far it has not been possible to test this assumption, though, because data on employed job searchers is not available to our knowledge.

\section{The Ordinary Matching Function}

Formally, the matching function can be written:

$$
h=A m(U, V)
$$

where $h$ are new hirings (matches, outflows from unemployment into employment), $U$ and $V$ are the stocks of unemployed persons and vacancies, respectively, and $m$ is a continuous non-constant function. $A$ is the mismatch parameter (the higher $A$, the smaller the mismatch between the unemployed and vacancies). Thus $A$ can capture a variety of factors. Amongst the most important are occupational mismatch, geographical mismatch, the efficiency of labour market institutions like the public employment service in creating matches, as well as preferences and institutionally set incentives which influence the search behaviour of the agents.

Specifying the matching process by a Cobb-Douglas production function we get

$$
h=A U^{\beta} V^{\gamma}
$$

Taking logarithms on both sides and allowing for some random variation in hirings, we can formulate the following regression equation

$$
\ln \left(h_{t}\right)=\alpha+\beta \ln \left(U_{t}\right)+\gamma \ln \left(V_{t}\right)+\delta t+\varepsilon_{t}
$$

where $\ln \left(A_{t}\right)=\alpha+\delta t+\varepsilon_{t} . \delta$ is the coefficient on the deterministic time trend which accounts for changes in matching efficiency over time. 


\section{The Augmented Matching Function}

In the ordinary matching function, the unemployed are treated as a homogenous pool of people. Lehmann (1995) taking up the concept of the search effectiveness of the unemployed by Layard, Nickell, and Jackman (1991, Chapters 5 and 10) formulates the augmented matching function as

$$
h=A(\psi U)^{\beta} V^{\gamma}
$$

where $\psi U$ denotes the search effective stock of the unemployed, and $\psi$ is the average search effectiveness of the unemployed people. The search effectiveness of the unemployment stock may be reduced by a higher share of the long-term unemployed in the total unemployment stock. ALMPs, on the other hand, can be viewed as measures to increase the search effectiveness of the unemployment stock. Following Lehmann (1995), we can thus decompose $\psi$ as

$$
\begin{aligned}
& \Psi=\psi_{0}(1+\kappa T), \text { with } \\
& T=\sum_{r=1}^{R} w_{r} T_{r} \text {, and } \sum_{r=1}^{R} w_{r}=1 \\
& \text { sothat } \psi=\psi_{0}+\psi_{0} \kappa w_{1} T_{1}+\psi_{0} \kappa w_{2} T_{2}+\ldots+\psi_{0} \kappa w_{R} T_{R}
\end{aligned}
$$

where $\psi_{0}\left(0<\psi_{0} \leq 1\right)$ is the search effectiveness index without any ALMP treatment, $T$ is a weighted ALMP index of the set of $R$ different ALMP programmes $T_{r}$. The $T_{r}$ variables can be expenditures on ALMPs, stocks or outflows of participants, or a combination of expenditures and participants in the programmes. $\psi_{0} \mathrm{~K}$ is the effect of the ALMP programmes on the search effectiveness of the unemployed.

Inserting the decomposition of $\psi$ into the Cobb-Douglas specification and taking logarithms we get:

$$
\begin{gathered}
\ln (h)=\ln (A)+\beta \ln \left(\psi_{0}(1+\kappa T)\right)+\beta \ln (U)+\gamma \ln (V) \\
\ln (h)=\ln (A)+\beta \ln \left(\psi_{0}\right)+\beta \ln (1+\kappa T)+\beta \ln (U)+\gamma \ln (V)
\end{gathered}
$$

For small $\kappa T$ we can approximate the equation by

$$
\ln (h) \approx \ln (A)+\beta \ln \left(\psi_{0}\right)+\beta \kappa T+\beta \ln (U)+\gamma \ln (V)
$$

which is equal to

$$
\ln (h) \approx \ln (A)+\beta \ln \left(\psi_{0}\right)+\beta \kappa w_{1} T_{1}+\beta \kappa w_{2} T_{2}+\ldots+\beta \kappa w_{R} T_{R}+\beta \ln (U)+\gamma \ln (V) .
$$

We can therefore write the following regression equation: 


$$
\ln \left(h_{t}\right) \approx \alpha+\beta \ln \left(U_{t}\right)+\gamma \ln \left(V_{t}\right)+\phi_{1} T_{1 t}+\phi_{2} T_{2 t}+\ldots \phi_{R} T_{R t}+\delta t+\varepsilon_{t}
$$

where $\phi_{r}=\beta \kappa w_{r}$ and $\ln \left(A_{t}\right)=\alpha+\beta \ln \left(\psi_{0}\right)+\delta t+\varepsilon_{t}$. Thus we can estimate the effects $\phi_{1}, \ldots, \phi_{R}$, of the active labour market programmes 1 to $R$ on the outflows from unemployment to employment $h$. In the following section, we survey the previous literature on augmented matching functions on central and eastern European transition economies.

\section{Studies on Augmented Matching Functions for Transition Economies}

The literature on augmented matching functions that estimate the effects of active labour market programmes has so far mainly concentrated on transition economies, although there are related approaches for western Germany and Britain (Haskel and Jackman, 1988; Disney et al., 1992). In the following, we focus on the results obtained for transition economies. There are studies on the Czech and Slovak Republics (Burda and Lubyova, 1995; Svejnar, Terrell, and Münich, 1995; and Boeri and Burda, 1996) and there is also some evidence on Poland in Lehmann (1995), Góra, Lehmann, Socha, and Sztanderska (1996), Puhani and Steiner (1996; 1997), and Kwiatkowski and Tokarski (1997). We have found one study on Bulgaria by Lenkova (1997), one on eastern Germany by Steiner et al. (1998), but have seen no evidence on Hungary so far. Where possible, we have calculated the estimated costs of increasing the outflow from unemployment into employment by one person through ALMP programmes in euro. ${ }^{1}$ Table 1 on page 6 summarises the main findings of the surveyed articles.

\footnotetext{
${ }^{1}$ During the observation period, the euro did not exist yet. We take $€ 1$ to be ECU 1 .
} 
Table 1: Summary of Studies on Augmented Matching Functions for Transition Economies

\begin{tabular}{|c|c|c|c|}
\hline Study & Country & Data & Main Findings \\
\hline \multirow[t]{2}{*}{$\begin{array}{l}\text { Burda and Lubyova } \\
\text { (1995) }\end{array}$} & $\begin{array}{l}\text { Czech } \\
\text { Republic }\end{array}$ & $\begin{array}{l}\text { 1992-1994 monthly panel for } \\
76 \text { labour office districts }\end{array}$ & $\begin{array}{l}\text { Positive effects of ALMP expenditure, positive effects of } \\
\text { participants in ALMPs only in specification without lagged } \\
\text { dependent variables; CRS not rejected; } \\
\text { Estimated costs of an additional outflow: CSK 132,000 } \\
\approx € 3,428\end{array}$ \\
\hline & $\begin{array}{l}\text { Slovak } \\
\text { Republic }\end{array}$ & $\begin{array}{l}1992-1993 \text { monthly panel for } \\
38 \text { labour office districts }\end{array}$ & $\begin{array}{l}\text { Positive effects of ALMP expenditure; no effects of labour } \\
\text { office staff; CRS not rejected; } \\
\text { Estimated costs of an additional outflow: CSK } 40,500 \\
\approx € 1,052\end{array}$ \\
\hline \multirow[t]{2}{*}{$\begin{array}{l}\text { Svejnar, Terrell, and } \\
\text { Münich (1995) }\end{array}$} & $\begin{array}{l}\text { Czech } \\
\text { Republic }\end{array}$ & $\begin{array}{l}1992-1993 \text { annual cross } \\
\text { sections }\end{array}$ & $\begin{array}{l}\text { Positive effect of ALMP expenditure per capita; } \\
\text { Estimated costs of an additional outflow: CSK } 69,616 \\
\approx € 1,808\end{array}$ \\
\hline & $\begin{array}{l}\text { Slovak } \\
\text { Republic }\end{array}$ & $\begin{array}{l}1992-1993 \text { annual cross } \\
\text { sections }\end{array}$ & no effect of ALMP expenditure per capita \\
\hline $\begin{array}{l}\text { Lehmann (1995); and } \\
\text { Góra, Lehmann, Socha, } \\
\text { and Sztanderska (1996) }\end{array}$ & Poland & $\begin{array}{l}1993-1994 \text { quarterly panel for } \\
49 \text { voivodships }\end{array}$ & no effect of training expenditure \\
\hline $\begin{array}{l}\text { Puhani and Steiner } \\
(1996 ; 1997)\end{array}$ & Poland & $\begin{array}{l}1993-1994 \text { quarterly panel for } \\
49 \text { voivodships }\end{array}$ & $\begin{array}{l}\text { no effects of expenditure on training, intervention works, nor } \\
\text { public works }\end{array}$ \\
\hline Boeri and Burda (1996) & $\begin{array}{l}\text { Czech } \\
\text { Republic }\end{array}$ & $\begin{array}{l}\text { 1991-1994 quarterly panel for } \\
76 \text { labour office districts }\end{array}$ & $\begin{array}{l}\text { Positive effect of ALMP expenditure; } \\
\text { Estimated costs of an additional outflow: CSK } 43,000 \\
\approx € 1,250 \text { (both numbers given by authors) }\end{array}$ \\
\hline
\end{tabular}


Table 1: Summary of Studies on Augmented Matching Functions for Transition Economies (ctd.)

\begin{tabular}{|c|c|c|c|}
\hline Study & Country & Data & Main Findings \\
\hline Lenkova (1997) & Bulgaria & 1994-1996 monthly time series & $\begin{array}{l}\text { no effects of training; Cobb-Douglas functional form not } \\
\text { rejected in favour of CES; increasing returns to scale, } \\
\text { although CRS not tested }\end{array}$ \\
\hline $\begin{array}{l}\text { Kwiatkowski and } \\
\text { Tokarski (1997) }\end{array}$ & Poland & $\begin{array}{l}1992-1996 \text { quarterly panel for } \\
49 \text { voivodships }\end{array}$ & $\begin{array}{l}\text { positive effects of intervention works, negative effects of } \\
\text { public works and loans to enterprises, no effects of training } \\
\text { and start-up loans; } \\
\text { estimated costs of an additional outflow through intervention } \\
\text { works: new PLZ } 1,318 \\
\approx € 446\end{array}$ \\
\hline Steiner et al. (1998) & $\begin{array}{l}\text { Eastern } \\
\text { Germany }\end{array}$ & $\begin{array}{l}\text { 1992-1997 monthly panel for } \\
35 \text { labour office districts }\end{array}$ & $\begin{array}{l}\text { Very small positive effect of outflows from training } \\
\text { programmes (Fortbildungs- und Umschulungsmaßnahmen, } \\
F u U \text { ) on outflows from unemployment; elasticity = } 0.1 \\
\text { CRS not rejected }\end{array}$ \\
\hline
\end{tabular}

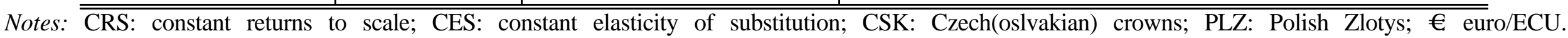
Source: exchange rates are taken from Deutsche Bundesbank (1992). 
The research carried out so far on empirical matching functions in both western and eastern European countries suggests that the Cobb-Douglas specification of the matching process provides an adequate description in most cases. The assumption of a constant returns to scale matching function is in many cases empirically rejected. However, Burda (1993) argues that this might be due to measurement bias, as firms report vacancies more frequently when the labour market is tight. In addition, the articles by Entorf (1995) as well as Burda and Profit (1996) show that misspecification of the dynamics can lead to a rejection of the constant returns to scale hypothesis.

Some authors have extended the standard specification by including the short-term and the long-term unemployment pool as separate regressors. Here the results differ between the United States and the central and eastern European transition economies. Whereas the long-term unemployed exhibit the same search effectiveness as the short-term unemployed in the United States (Blanchard and Diamond, 1989; 1990), the long-term unemployed seem to be much more detached and/or excluded from the labour market in central and eastern Europe (Boeri, 1994a; 1994b; Lehmann; 1995; Góra, Lehmann, Socha, and Sztanderska, 1996; Kwiatkowski and Tokarski, 1997). Moreover, it has been shown that the matching mechanism works differently in various types of regions (diversified/modern, industrial, and agricultural ones), although no clear pattern has emerged from these results (Boeri and Scarpetta, 1995; Burda and Profit, 1996).

As to the effects of ALMPs estimated from augmented matching functions, the general results for the Czech Republic, Slovakia, Bulgaria, and Poland seem to be mixed. Some studies find significant positive effects (Burda and Lubyova, 1995; Svejnar, Terell, and Münich, 1995; Boeri and Burda, 1996; Kwiatkowski and Tokarski, 1997), others cannot detect any impacts (Lehmann, 1995; Góra, Lehmann, Socha, and Sztanderska, 1996; Puhani and Steiner, 1996; 1997; Lenkova, 1997). Kwiatkowski and Tokarski (1997) even find negative effects of public works and loans to enterprises on outflows from unemployment. When positive effects of ALMPs show up, the estimated costs to get an unemployed worker back into employment by way of ALMP programmes range between $€ 1,250$ and $€ 3,430$ for the Czech Republic (Burda and Lubyova, 1995; Svejnar, Terrell, and Münich, 1995; Boeri and Burda, 1996). Further, these costs were estimated to be $€ 1,052$ for Slovak ALMPs (Burda and Lubyova, 1995) and $€ 446$ for Polish intervention works (Kwiatkowski and Tokarski, 1997).

An important econometric issue addressed in Burda and Wyplosz (1994) is the potential non-stationarity of the time series, which can lead to spurious regression results. Further, the dynamics of labour market flows have been modelled econometrically by experimenting with lagged dependent and independent variables (Blanchard and Diamond, 1989; 1990; Entorf, 1995; Boeri and Burda, 1996). As 
pointed out by Boeri and Burda (1996), the question of endogeneity of the ALMP variables is very important. Expenditures on ALMPs are in most countries allocated to regional units according to the severity of the local labour market situation. As a consequence, ALMP expenditure or participants variables may themselves be dependent on outflows from unemployment. This endogeneity will most likely lead to biased estimation results. Therefore, we address issues of dynamics and the possible endogeneity of ALMPs in the empirical analysis below (see Sections 5 and 6). Before that we will present the data for Poland, though.

\section{Data and Variables}

We use two types of data. Our first data source is quarterly panel data from the Polish Ministry of Labour and Social Policy ${ }^{2}$ on outflows from unemployment, unemployment and vacancy stocks, as well as expenditures on the Polish ALMP programmes (training, intervention works, public works, start-up loans, and loans for enterprises). The data are available to us for all 49 voivodships between the first quarter of 1992 until the last quarter of 1995. Some series also start during the last quarter of 1991 and/or end at the first quarter of 1996.

Our second data source is the Polish Labour Force Survey (PLFS), which is a quarterly survey of the Polish labour force which started in May 1992. The sample size is around 50,000 persons each wave. Sampling in the PLFS takes place by randomly drawing a number of households from Poland's territorial statistical units (TSUs) proportional to the population share of the TSUs. From the households drawn, all members aged 15 and above are interviewed. Excluded from the possibility of interview are the non-housing population (essentially the homeless, people in group quarters, soldiers doing compulsory military service and the prison population) and people living abroad at the time of interview. The PLFS is thus only representative for the Polish population that does not fall into any of these categories. Another factor limiting the representative character of the PLFS is the fact that the non-interview rate varies with the size of the place of residence. Whereas this rate was 6.5 percent in August 1993 for the whole of Poland, it was 24 percent in Warsaw, but only 1.6 percent in rural communities (Szarkowski and Witkowski, 1994). However, for the other place-of-residence categories mentioned in Szarkowski and Witkowski (1994), the highest non-interview rate is 8.2 percent and the lowest 4.5 percent, so that the PLFS may show some, but hopefully not too severe distortions in terms of representative character.

We can use the PLFS to calculate outflow rates from unemployment into employment and vice versa. The advantage of using PLFS data lies in the fact that

\footnotetext{
${ }^{2}$ We thank Professor Eugeniusz Kwiatkowski, University of Lodz, for sending us this data.
} 
the classification of individuals into the three labour force states employment, unemployment, and non-participation follows the definitions of the International Labour Office (ILO). Accordingly, classified as employed are people who during the week of interview earn money for at least one hour or who hold a job, but do not work temporarily (e.g. because they are ill). Additionally, so-called unpaid family workers are also classified as employed. Those people not employed are classified as unemployed if they actively search for a job and are also ready to start work in the week of interview or the following one. Anybody not falling into either of the two labour force states employment or unemployed is classified as not being in the labour force.

In order to estimate the total numbers of unemployed people and outflows from unemployment from the PLFS, we divide the figures in the PLFS by the share of people interviewed out of the total voivodship population. To calculate this share, we need figures for the population aged 15 and above. Unfortunately, we were not able to obtain this series, but only figures for the total population of Poland. Yet as far as the population share of this age group did not change very much over the observation period, the scaling error in our data will not bias any econometric estimates except constant terms.

Figure 1 and Figure 2 compare the developments of the unemployment stock as well as outflows from unemployment variables as measured in the register and PLFS data, respectively. The figures depict the time series for the whole of Poland, which was obtained by adding up the data for the 49 voivodships. 
Figure 1: The Development of Unemployment in Poland

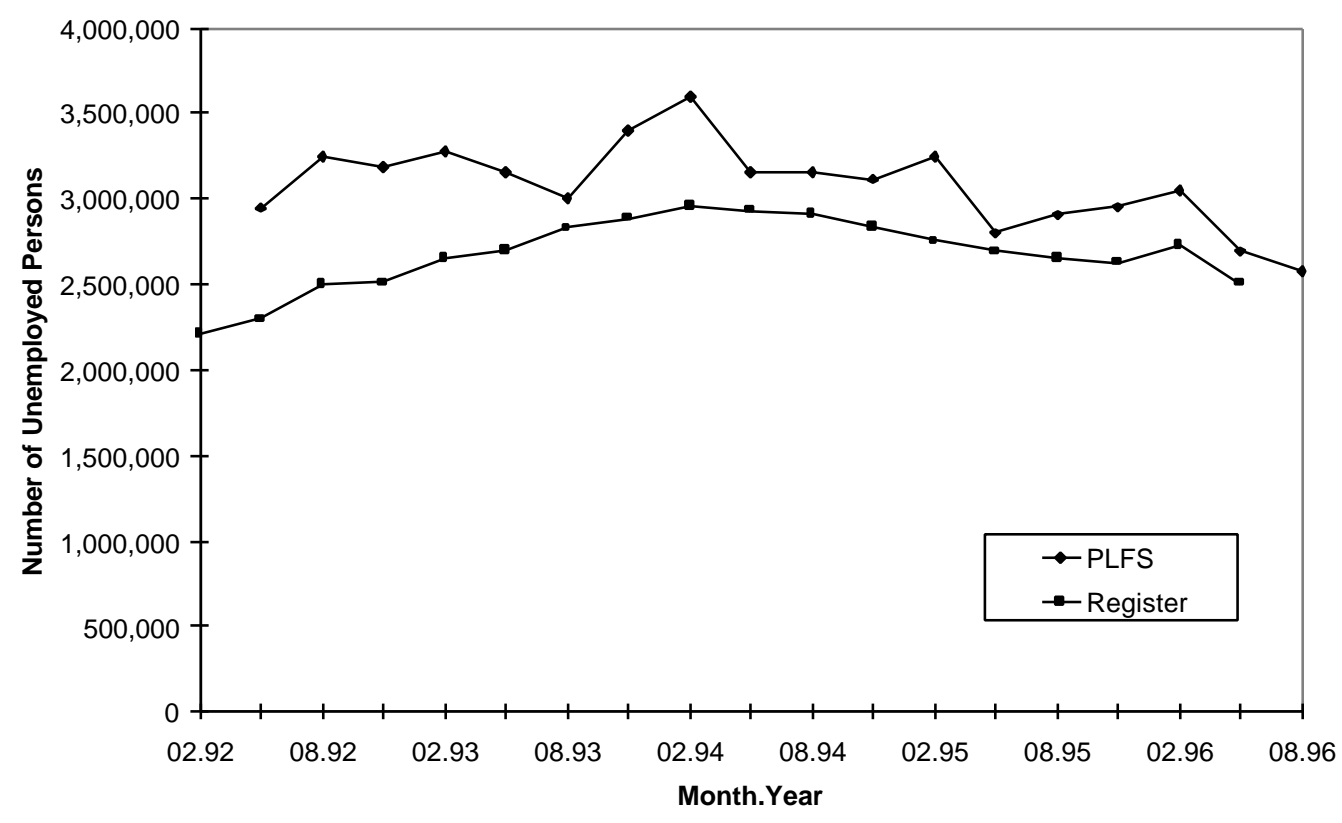

Sources: Polish Labour Force Survey (PLFS); Polish Ministry of Labour and Social Policy (Register); own calculations.

\section{Figure 2: The Development of Outflows from Unemployment in Poland}

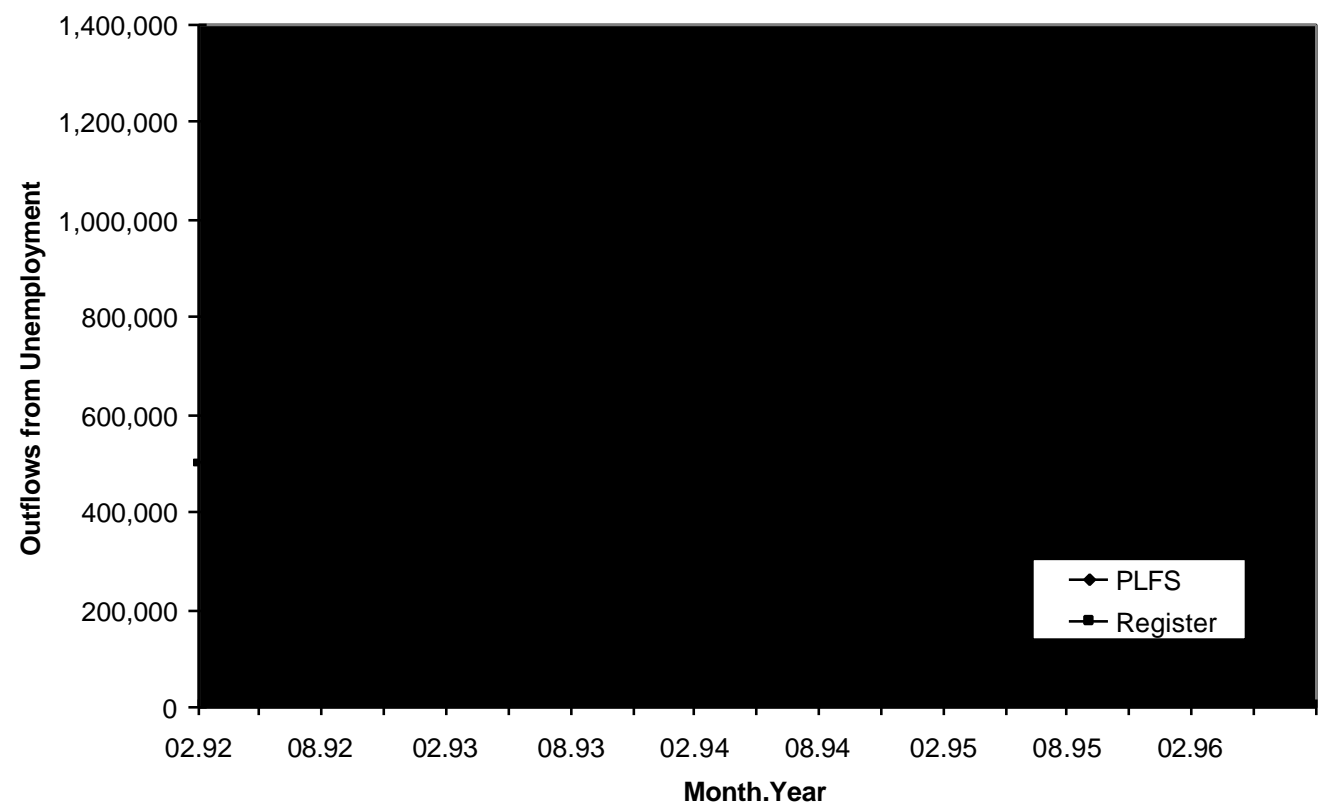

Sources: Polish Labour Force Survey (PLFS); Polish Ministry of Labour and Social Policy (Register); own calculations. 
Figure 1 shows that the unemployment stock is generally higher in the PLFS than in the register data. This, however, is almost surely due to the just mentioned scaling effect which occurs through the inclusion of people under 15 years of age in the calculation of the population shares sampled in the PLFS. Kalaska and Witkowski (1997) demonstrate that unemployment figures obtained from the PLFS are generally lower than those from the register. Furthermore, the PLFS data show a greater seasonal variation in unemployment than the register data. This is not an unexpected result, as the register data are likely to be stronger driven by institutional factors such as entitlement to unemployment benefit for a fixed period of usually 12 months. The PLFS data can be expected to reflect the search behaviour of the unemployed more accurately due to the application of the ILO definition of unemployment.

An even greater difference between the PLFS and register data emerges when looking at the outflows from unemployment in Figure 2. The fact that the register data exhibits higher outflows for most months is not surprising, as the register data measures total outflows from the registers, whereas the PLFS data only measures outflows to employment, which is what we are interested in. When using the total outflows data from the register (because outflows to jobs are not available to us on the voivodship level) we hope the movements in the two series to be proportional. In this case, any estimation results would still be unbiased. However, as can be seen from Figure 2, this proportionality assumption does not seem to hold between the two data sources we observe here. Unfortunately, though, we cannot make a clear statement on the validity of the proportionality assumption, as the difference in the two series may stem from many factors. One is the just mentioned difference in the type of outflow measures. Another one is the different definition of unemployment. Further, the different data source per se may play a role. And finally, there might be estimation errors when inferring from the PLFS on the total population.

The just discussed differences in concepts and measurements between the data sources at hand warrant a sensitivity analysis with respect to the data set used. Descriptive statistics for the data from both the Polish Ministry of Labour and Social Policy and the Polish Labour Force Survey are presented in Table 2. 
Table 2: $\quad$ Descriptive Statistics for Panel Data

\begin{tabular}{|c|c|c|c|c|c|c|c|}
\hline Variable & Data & Mean & S.d. & Min. & Max. & \multicolumn{2}{|c|}{ Observations } \\
\hline $\begin{array}{l}\text { In outflows from } \\
\text { unemployment } \\
\text { (PLFS) }\end{array}$ & $\begin{array}{c}\text { overall } \\
\text { between } \\
\text { within }\end{array}$ & 2.149 & $\begin{array}{l}0.745 \\
0.473 \\
0.583 \\
\end{array}$ & $\begin{array}{l}0.352 \\
1.044 \\
0.033\end{array}$ & $\begin{array}{l}4.377 \\
3.461 \\
4.311 \\
\end{array}$ & $\begin{array}{l}N_{\text {it }} \\
N_{i} \\
\bar{N}\end{array}$ & $\begin{array}{c}818 \\
49 \\
16.69\end{array}$ \\
\hline $\begin{array}{l}\text { In unemployment stock } \\
\text { (PLFS) }\end{array}$ & $\begin{array}{c}\text { overall } \\
\text { between } \\
\text { within } \\
\end{array}$ & 4.020 & $\begin{array}{l}0.490 \\
0.463 \\
0.172 \\
\end{array}$ & $\begin{array}{l}2.437 \\
2.890 \\
3.395 \\
\end{array}$ & $\begin{array}{l}5.519 \\
5.418 \\
4.587 \\
\end{array}$ & $\begin{array}{l}N_{i t} \\
N_{i} \\
N_{t}\end{array}$ & $\begin{array}{c}882 \\
49 \\
18 \\
\end{array}$ \\
\hline $\begin{array}{l}\text { In outflows from } \\
\text { unemployment } \\
\text { (register) }\end{array}$ & $\begin{array}{c}\text { overall } \\
\text { between } \\
\text { within } \\
\end{array}$ & 2.088 & $\begin{array}{l}0.604 \\
0.437 \\
0.421 \\
\end{array}$ & $\begin{array}{l}-0.223 \\
1.146 \\
0.198 \\
\end{array}$ & $\begin{array}{l}3.813 \\
3.365 \\
3.251 \\
\end{array}$ & $\begin{array}{l}N_{i t} \\
N_{i} \\
N_{t}\end{array}$ & $\begin{array}{c}833 \\
49 \\
17 \\
\end{array}$ \\
\hline $\begin{array}{l}\text { In unemployment stock } \\
\text { (register) }\end{array}$ & $\begin{array}{c}\text { overall } \\
\text { between } \\
\text { within } \\
\end{array}$ & 3.903 & $\begin{array}{l}0.427 \\
0.417 \\
0.111 \\
\end{array}$ & $\begin{array}{l}2.451 \\
2.786 \\
3.459 \\
\end{array}$ & $\begin{array}{l}5.179 \\
5.037 \\
4.184 \\
\end{array}$ & $\begin{array}{l}N_{i t} \\
N_{i} \\
N_{t}\end{array}$ & $\begin{array}{c}882 \\
49 \\
18 \\
\end{array}$ \\
\hline $\begin{array}{l}\text { In outflows from } \\
\text { employment } \\
\text { (PLFS) }\end{array}$ & $\begin{array}{c}\text { overall } \\
\text { between } \\
\text { within }\end{array}$ & 1.853 & $\begin{array}{l}0.685 \\
0.413 \\
0.554 \\
\end{array}$ & $\begin{array}{r}0.353 \\
1.036 \\
-0.063 \\
\end{array}$ & $\begin{array}{l}4.377 \\
2.856 \\
4.300 \\
\end{array}$ & $\begin{array}{c}N_{i t} \\
N_{i} \\
\bar{N} \\
\end{array}$ & $\begin{array}{c}799 \\
49 \\
16.31 \\
\end{array}$ \\
\hline $\begin{array}{l}\text { In employment stock } \\
\text { (PLFS) }\end{array}$ & $\begin{array}{c}\text { overall } \\
\text { between } \\
\text { within }\end{array}$ & 5.847 & $\begin{array}{l}0.498 \\
0.499 \\
0.063 \\
\end{array}$ & $\begin{array}{l}4.732 \\
4.845 \\
5.627 \\
\end{array}$ & $\begin{array}{l}7.569 \\
7.478 \\
6.071 \\
\end{array}$ & $\begin{array}{l}N_{i t} \\
N_{i} \\
N_{t}\end{array}$ & $\begin{array}{c}882 \\
49 \\
18 \\
\end{array}$ \\
\hline $\begin{array}{l}\text { In vancancy stock } \\
\text { (register) }\end{array}$ & $\begin{array}{c}\text { overall } \\
\text { between } \\
\text { within }\end{array}$ & 0.927 & $\begin{array}{l}0.827 \\
0.684 \\
0.475 \\
\end{array}$ & $\begin{array}{l}-2.303 \\
-0.364 \\
-1.185 \\
\end{array}$ & $\begin{array}{l}3.211 \\
2.734 \\
2.312 \\
\end{array}$ & $\begin{array}{l}N_{i t} \\
N_{i} \\
N_{t}\end{array}$ & $\begin{array}{c}833 \\
49 \\
17 \\
\end{array}$ \\
\hline $\begin{array}{l}\text { expenditure on training } \\
\text { (register) }\end{array}$ & $\begin{array}{l}\text { overall } \\
\text { between } \\
\text { within } \\
\end{array}$ & 0.308 & $\begin{array}{l}0.441 \\
0.343 \\
0.282 \\
\end{array}$ & $\begin{array}{r}0.000 \\
0.015 \\
-1.342 \\
\end{array}$ & $\begin{array}{l}3.808 \\
1.816 \\
2.300 \\
\end{array}$ & $\begin{array}{l}N_{i t} \\
N_{i} \\
N_{t}\end{array}$ & $\begin{array}{l}784 \\
49 \\
16 \\
\end{array}$ \\
\hline $\begin{array}{l}\text { expenditure on } \\
\text { intervention works } \\
\text { (register) }\end{array}$ & $\begin{array}{c}\text { overall } \\
\text { between } \\
\text { within }\end{array}$ & 1.109 & $\begin{array}{l}0.955 \\
0.673 \\
0.684 \\
\end{array}$ & $\begin{array}{r}0.034 \\
0.255 \\
-1.483 \\
\end{array}$ & $\begin{array}{l}6.038 \\
3.141 \\
4.638 \\
\end{array}$ & $\begin{array}{l}N_{i t} \\
N_{i} \\
N_{t}\end{array}$ & $\begin{array}{l}784 \\
49 \\
16 \\
\end{array}$ \\
\hline $\begin{array}{l}\text { expenditure on public } \\
\text { works } \\
\text { (register) } \\
\end{array}$ & \begin{tabular}{|c} 
overall \\
between \\
within \\
\end{tabular} & 0.887 & $\begin{array}{l}1.019 \\
0.630 \\
0.805 \\
\end{array}$ & $\begin{array}{r}0.000 \\
0.108 \\
-1.818 \\
\end{array}$ & $\begin{array}{l}6.252 \\
2.705 \\
4.867 \\
\end{array}$ & $\begin{array}{l}N_{i t} \\
N_{i} \\
N_{t}\end{array}$ & $\begin{array}{l}784 \\
49 \\
16 \\
\end{array}$ \\
\hline $\begin{array}{l}\text { expenditure on loans for } \\
\text { the unemployed } \\
\text { (register) }\end{array}$ & $\begin{array}{c}\text { overall } \\
\text { between } \\
\text { within }\end{array}$ & 0.156 & $\begin{array}{l}0.256 \\
0.116 \\
0.229 \\
\end{array}$ & $\begin{array}{r}0.000 \\
0.002 \\
-0.573 \\
\end{array}$ & $\begin{array}{l}4.554 \\
0.730 \\
3.980 \\
\end{array}$ & $\begin{array}{l}N_{i t} \\
N_{i} \\
N_{t}\end{array}$ & $\begin{array}{c}784 \\
49 \\
16 \\
\end{array}$ \\
\hline $\begin{array}{l}\text { expenditure on loans for } \\
\text { enterprises } \\
\text { (register) }\end{array}$ & $\begin{array}{l}\text { overall } \\
\text { between } \\
\text { within }\end{array}$ & 0.117 & $\begin{array}{l}0.270 \\
0.161 \\
0.217\end{array}$ & $\begin{array}{c}0.000 \\
0.001 \\
-0.723\end{array}$ & $\begin{array}{l}3.225 \\
0.840 \\
2.587\end{array}$ & $\begin{array}{l}N_{i t} \\
N_{i} \\
N_{t}\end{array}$ & $\begin{array}{c}784 \\
49 \\
16 \\
\end{array}$ \\
\hline
\end{tabular}

Notes: The between data are formed by calculating the means over time by voivodship $\bar{x}_{i}$; the within data are defined as $x_{i t}-\bar{x}_{i .}+\overline{\bar{x}}$, where the overall mean $\overline{\bar{x}}$ is added to equate the mean of all data (overall, between, and within); the unemployment and vacancy data are in logarithms ( $(n)$ of thousands, and ALMP expenditure is in million real new PLZ (1995); S.d.: standard deviation.

Sources: Polish Labour Force Survey (PLFS); Polish Ministry of Labour and Social Policy (Register); own calculations. 
For some voivodships in the PLFS, we measure zero flows from unemployment to employment or vice versa between two quarters. As in these voivodships only a small number of people is sampled, zero flows in the sample should not be inferred for the whole population. We therefore drop such observations. As a consequence, the panel becomes unbalanced. Although the missing values are not random, they will be treated as such, as their number is small and any method to model the occurrence of missing values has to invoke additional assumptions.

The observation period generally goes from the first quarter of 1992 (second quarter for PLFS data) to the last quarter of 1995. The register data are identical to those of Kwiatkowski and Tokarski (1997). Boeri (1994a; 1994b) has a shorter observation period from January 1992 to March 1993, but more observations, as his panel has monthly time-series information. He states an OECD database as his data source which is probably obtained from the Polish registers. Lehmann (1995), and Góra, Lehmann, Socha, and Sztanderska (1996) also have a shorter observation period than us: they use quarterly register data from the first quarter of 1993 to the second quarter of 1994. The only other studies on Poland also using PLFS data are the ones by Puhani and Steiner (1996; 1997), who use PLFS data for the outflow variable and combine them with administrative data on ALMP expenditures. The observation period in these studies (1992 to 1993) is also shorter than in this work. As we have the conceptual problem that outflows into any ALMP apart from training are measured as outflows into employment, we can only identify the effects of training, but not of any other ALMP programme, in our data.

Table 2 not only reports standard deviations for the pooled panel data (overall), but also for the between (means over time) and within (deviation from means over time) data. Glancing over the sizes of the standard deviations, we find both large within and between variation in all variables. The fixed effects panel estimator only makes use of the within information. However, the existence of a considerable between variation in the data makes the random effects panel estimator potentially more attractive, because it also makes use of the between information in the data. Therefore, we will present both fixed and random effects models below.

\section{Econometric Issues}

Following Puhani and Steiner (1996; 1997), the endogeneity problem will be addressed by lagging the ALMP variables. Lagging the ALMP expenditure variables also accounts for the fact that it takes some time until these expenditures can have an effect on the labour market. We also check the sensitivity of the results with respect to the inclusion of current ALMP expenditure in the panel estimations. 


\section{Inconsistency due to Lagged Dependent Variables in Panel Estimations}

It can be shown that both fixed and random effects estimators can be expressed as OLS estimators on transformed models (see, e.g. Baltagi, 1995, Chapter 2) It can also be shown that the inclusion of a lagged dependent variable amongst the regressors will induce a correlation between the error term and the regressors, because the mean of the error terms over time is by definition correlated with the dependent variable. In the random effects case, the problem is even more severe, as the lagged dependent variables are also correlated with the error term through the unit-specific effects. Therefore, estimates with lagged dependent variables in panel data will be inconsistent for fixed $N_{t}$ and $N_{i} \rightarrow \infty$.

As a solution to this problem, instrumental variable estimators on a model in first differences have been proposed in the literature ( $c f$. Greene, 1997, Chapter 14). Moreover, generalised method of moments estimators have been developed (Ahn and Schmidt, 1995). However, Monte Carlo evidence suggests that the fixed effects estimator, although biased, has a relatively small variance compared to the instrumental variable and generalised method of moments estimators and therefore does not necessarily perform worse in terms of mean square error (Kiviet, 1995). The induced correlation through the inclusion of a lagged dependent variable is of order $1 / N_{t}$. That is to say, the greater $N_{t}$, the lower the induced correlation. As in our matching function analyses below, $N_{t}$ will always be greater than eleven, we hope that the problem of induced autocorrelation is attenuated in the fixed effects models. But as we generally work in a small sample context, all proposed panel estimators in the face of lagged dependent variables must be expected to yield biased results.

Weighing up the Monte Carlo research by Kiviet (1995) we choose to apply the fixed effects estimator because of its comparatively small dispersion (the random effects estimates are also reported for comparative purposes). This has been the approach in all studies surveyed above which include lagged dependent variables in panel settings (Burda and Lubyova, 1995; Boeri and Burda, 1996; and Burda and Profit, 1996). Although we will see below that the inclusion of lagged dependent variables does not make a qualitative difference to the estimation results obtained, it must be stressed that the estimation results with lagged dependent variables have to be interpreted with a caveat.

\section{Estimation Results}

In the following two sections we report the estimation results. We do not use any information on intervention or public works, though. We can only estimate the effect of training measures, and no other ALMP programmes, on the outflows from unemployment. The reason is that the total outflow as well as outflows to jobs 
variables include outflows to intervention and public works. Therefore, by definition an inflow into a works programme leads to an outflow from the unemployment register. Regressing any type of outflows on works programmes variables must consequently yield upward-biased estimates. As trainees, unlike works programme participants, stay on the unemployment register, training effects are identifiable from our data. Section 6.1 presents the estimates of training expenditures on outflows from unemployment. We can however, estimate the effects of all five ALMP programmes on the outflows from employment. These are presented in Section 6.2.

\subsection{Panel Evidence on the Effects of Training on the Outflows from Unemployment}

In the following, we present estimates of augmented matching functions on our panel data sets. We first discuss the results on the data from the Polish registers and then compare them with the ones from the Polish Labour Force Survey (PLFS). As outlined in Section 4, only training programmes are evaluated here, because participation in any other programme is measured as an outflow into employment. Thus estimates on the other programmes would be biased. Because of the large enough sample size, we will nevertheless include current expenditures on the other ALMP programmes as control variables. Some of them turn out to be significant, but they will not be discussed any further because it is difficult to make a statement on the size of the bias.

\section{Estimates Based on Register Data}

Table 3 and Table 4 show the augmented matching function estimates on the panel data from the Polish registers. The specifications in Table 4 unlike those in Table 3 include lagged dependent variables. Each table reports four regression results: because of the potential endogeneity of training expenditures and the fact that it takes time for these expenditures to become effective, we check whether the exclusion of current expenditure makes any difference to the results. Furthermore, we estimate each specification by both fixed and random effects models. In case the Hausman (1978) test does not reject the random effects model, the random effects estimates are more efficient than the fixed effects estimates.

The coefficient on unemployment is significant in all specifications and even larger than the one on vacancies. This has also been found in the other studies on Poland using panel data (see Boeri, 1994a; 1994b; Boeri and Scarpetta, 1995; Lehmann, 1995; and Kwiatkowski and Tokarski, 1997). Random effects are rejected in favour of fixed effects in all equations by the Hausman test. Constant returns to scale in matching are not rejected in the specifications without lagged dependent variables (Table 3). However, they are rejected in favour of increasing returns to scale when lagged dependent variables are included (Table 4). Increasing returns to scale have 
not been found in previous studies on Poland. However, the difference between our results and those of the other studies summarised above has an econometric explanation. Neither Boeri (1994b), Boeri and Scarpetta (1995), Lehmann (1995), nor Kwiatkowski and Tokarski (1997) control for voivodship effects. They simply estimate pooled panel regressions. Only Boeri (1994a) estimates a random effects model, but he rejects this specification by the Hausman test. Another difference to the other studies on Poland is that they do not include lagged dependent variables. 
Table 3: $\quad$ Augmented Matching Function Estimates with Register Data without Lagged Dependent Variables

\begin{tabular}{|c|c|c|c|c|c|c|c|c|}
\hline \multirow[t]{3}{*}{ Variable } & \multicolumn{4}{|c|}{ With current training expenditure } & \multicolumn{4}{|c|}{ Without current training expenditure } \\
\hline & \multicolumn{2}{|c|}{ Fixed effects } & \multicolumn{2}{|c|}{ Random effects } & \multicolumn{2}{|c|}{ Fixed effects } & \multicolumn{2}{|c|}{ Random effects } \\
\hline & Coeff. & t-value & Coeff. & $\mathrm{t}$-value & Coeff. & $\mathrm{t}$-value & Coeff. & $\mathrm{t}$-value \\
\hline $\begin{array}{l}\text { In unemployment (t- } \\
\text { 1) }\end{array}$ & 0.940 & 7.547 & 0.673 & 13.96 & 0.930 & 7.48 & 0.670 & 13.97 \\
\hline In vacancies ( $\mathrm{t}-1)$ & 0.122 & 4.596 & 0.192 & 9.02 & 0.124 & 4.66 & 0.190 & 8.94 \\
\hline $\begin{array}{l}\text { Training } \\
\text { expenditure }\end{array}$ & -0.043 & -1.219 & -0.020 & -0.60 & - & - & - & - \\
\hline Training exp. (t-1) & 0.110 & 3.445 & 0.086 & 2.69 & 0.098 & 3.23 & 0.078 & 2.70 \\
\hline Training exp.(t-2) & -0.047 & -1.514 & -0.045 & -1.43 & -0.045 & -1.45 & -0.046 & -1.45 \\
\hline Training exp.(t-3) & $0.052^{*}$ & 1.759 & $0.055^{*}$ & 1.95 & 0.062 & 2.15 & 0.057 & 2.04 \\
\hline IW expenditure & -0.021 & -1.072 & -0.021 & -1.20 & -0.024 & -1.27 & -0.023 & -1.30 \\
\hline PW expenditure & 0.054 & 3.221 & 0.012 & 0.80 & 0.053 & 3.17 & 0.013 & 0.87 \\
\hline Start-up loans exp. & 0.246 & 6.419 & 0.212 & 5.55 & 0.238 & 6.30 & 0.207 & 5.58 \\
\hline Loans to ent. exp. & -0.005 & -0.138 & -0.032 & -0.90 & -0.016 & -0.48 & -0.038 & -1.13 \\
\hline \multicolumn{9}{|c|}{ (fixed time effects omitted) } \\
\hline Constant & -1.928 & -4.024 & -0.917 & -5.27 & -1.905 & -3.98 & -0.909 & -5.23 \\
\hline $\mathrm{R}^{2}$ overall & \multicolumn{2}{|c|}{0.831} & \multicolumn{2}{|c|}{0.869} & \multicolumn{2}{|c|}{0.832} & \multicolumn{2}{|c|}{0.869} \\
\hline$N_{i}$ & \multicolumn{2}{|c|}{49} & \multicolumn{2}{|c|}{49} & \multicolumn{2}{|c|}{49} & \multicolumn{2}{|c|}{49} \\
\hline$N_{t}$ & \multicolumn{2}{|c|}{13} & \multicolumn{2}{|c|}{13} & \multicolumn{2}{|c|}{13} & \multicolumn{2}{|c|}{13} \\
\hline F/LM test & \multicolumn{2}{|c|}{0.000} & \multicolumn{2}{|c|}{0.000} & \multicolumn{2}{|c|}{0.000} & \multicolumn{2}{|c|}{0.000} \\
\hline Hausman test & \multicolumn{2}{|c|}{-} & \multicolumn{2}{|c|}{0.000} & \multicolumn{2}{|c|}{ - } & \multicolumn{2}{|c|}{0.000} \\
\hline CRS test & \multicolumn{2}{|c|}{0.622} & \multicolumn{2}{|c|}{0.002} & \multicolumn{2}{|c|}{0.670} & \multicolumn{2}{|c|}{0.001} \\
\hline Joint training test & \multicolumn{2}{|c|}{0.006} & & & & & & \\
\hline Costs in PLZ & & & & & & & & \\
\hline Costs in $€$ & & & & & & & & \\
\hline
\end{tabular}

Notes: shaded coefficients are significant at the 5 percent level; asterisked coefficients are significant at the 10 percent level;

IW.: intervention works; PW.: public works; Ent.: enterprises; CRS: constant returns to scale;

' $\mathrm{R}^{2}$ overall' (as Stata calls it) is the correlation between the actual and predicted outflows;

the null hypothesis of the F/LM test is the non-existence of voivodship-specific effects; test results are reported in terms of p-values, which means that the null hypothesis is rejected at the 5 percent significance level if the p-value is smaller than 0.05 ;

the null hypotheses are non-existence of voivodship-specific effects; equality of random and fixed effects estimates; constant returns to scale; all training variables equal to zero;

the costs in PLZ and costs in $€$ are the estimated costs to increase the outflow from unemployment by one person (at the mean);

the time effects are quarterly dummies.

Source: Polish Ministry of Labour and Social Policy; own calculations. 
Table 4: Augmented Matching Function Estimates with Register Data with Lagged Dependent Variables

\begin{tabular}{|c|c|c|c|c|c|c|c|c|}
\hline \multirow[t]{3}{*}{ Variable } & \multicolumn{4}{|c|}{ With current training expenditure } & \multicolumn{4}{|c|}{ Without current training expenditure } \\
\hline & \multicolumn{2}{|c|}{ Fixed effects } & \multicolumn{2}{|c|}{ Random effects } & \multicolumn{2}{|c|}{ Fixed effects } & \multicolumn{2}{|c|}{ Random effects } \\
\hline & Coeff. & t-value & Coeff. & t-value & Coeff. & t-value & Coeff. & t-value \\
\hline $\ln$ outflows (t-1) & 0.315 & 7.78 & 0.376 & 9.92 & 0.315 & 7.78 & 0.376 & 9.94 \\
\hline $\ln$ outflows (t-2) & 0.129 & 3.59 & 0.130 & 3.60 & 0.130 & 3.69 & 0.130 & 3.64 \\
\hline $\ln$ outflows (t-3) & -0.027 & -0.88 & -0.034 & -1.13 & -0.027 & -0.88 & -0.034 & -1.13 \\
\hline $\ln$ outflows (t-4) & 0.141 & 5.72 & 0.131 & 5.55 & 0.141 & 5.72 & 0.131 & 5.57 \\
\hline In unemployment (t-1) & 1.425 & 9.87 & 0.338 & 10.42 & 1.424 & 9.87 & 0.339 & 10.44 \\
\hline In vacancies (t-1) & 0.038 & 1.37 & 0.072 & 4.03 & 0.038 & 1.38 & 0.072 & 4.05 \\
\hline Training expenditure & -0.007 & -0.20 & 0.001 & 0.04 & - & - & - & - \\
\hline Training exp. (t-1) & 0.076 & 2.37 & 0.046 & 1.43 & 0.074 & 2.49 & 0.046 & 1.80 \\
\hline Training exp.(t-2) & -0.062 & -2.15 & -0.083 & -2.83 & -0.062 & -2.15 & -0.083 & -2.84 \\
\hline Training exp.(t-3) & 0.065 & 2.39 & 0.042 & 1.68 & 0.067 & 2.52 & 0.042 & 1.68 \\
\hline IW expenditure & -0.012 & -0.63 & -0.009 & -0.69 & -0.013 & -0.67 & -0.009 & -0.69 \\
\hline PW expenditure & 0.026 & 1.57 & -0.014 & -1.28 & 0.026 & 1.56 & -0.014 & -1.29 \\
\hline Start-up loans exp. & 0.160 & 2.94 & 0.059 & 1.13 & 0.160 & 2.94 & 0.059 & 1.14 \\
\hline $\begin{array}{l}\text { Loans to enterprises } \\
\text { exp. }\end{array}$ & -0.024 & -0.69 & -0.026 & -0.79 & -0.026 & -0.77 & -0.026 & -0.82 \\
\hline \multicolumn{9}{|c|}{ (fixed time effects omitted) } \\
\hline Constant & -4.915 & -8.20 & -0.791 & -7.91 & -4.914 & -8.21 & -0.791 & -7.92 \\
\hline $\mathrm{R}^{2}$ overall & \multicolumn{2}{|c|}{0.8204} & \multicolumn{2}{|c|}{0.9205} & \multicolumn{2}{|c|}{0.8204} & \multicolumn{2}{|c|}{0.9205} \\
\hline$N_{i}$ & \multicolumn{2}{|c|}{49} & \multicolumn{2}{|c|}{49} & \multicolumn{2}{|c|}{49} & \multicolumn{2}{|c|}{49} \\
\hline$N_{t}$ & \multicolumn{2}{|c|}{12} & \multicolumn{2}{|c|}{12} & \multicolumn{2}{|c|}{12} & \multicolumn{2}{|c|}{12} \\
\hline $\mathrm{F} / \mathrm{LM}$ test & \multicolumn{2}{|c|}{0.000} & \multicolumn{2}{|c|}{0.247} & \multicolumn{2}{|c|}{0.000} & \multicolumn{2}{|c|}{0.247} \\
\hline Hausman test & \multicolumn{2}{|c|}{-} & \multicolumn{2}{|c|}{0.000} & \multicolumn{2}{|c|}{-} & \multicolumn{2}{|c|}{0.000} \\
\hline CRS test & \multicolumn{2}{|c|}{0.000} & \multicolumn{2}{|c|}{0.565} & \multicolumn{2}{|c|}{0.000} & & \\
\hline Joint training test & & & & & & & & \\
\hline Costs in PLZ & & & & & & & & \\
\hline Costs in $€$ & & & & & & & & \\
\hline
\end{tabular}

Notes: shaded coefficients are significant at the 5 percent level; asterisked coefficients are significant at the 10 percent level; IW.: intervention works; PW.: public works; Ent.: enterprises; CRS: constant returns to scale; 'R ${ }^{2}$ overall' (as Stata calls it) is the correlation between the actual and predicted outflows; the null hypothesis of the F/LM test is the non-existence of voivodship-specific effects; test results are reported in terms of p-values, which means that the null hypothesis is rejected at the 5 percent significance level if the p-value is smaller than 0.05 ; the null hypotheses are non-existence of voivodship-specific effects; equality of random and fixed effects estimates; constant returns to scale; all training variables equal to zero; the costs in PLZ and costs in $€$ are the estimated costs to increase the outflow from unemployment by one person; the time effects are quarterly dummies.

Source: Polish Ministry of Labour and Social Policy; own calculations. 
The estimates without lagged dependent variables in Table 3 show that training has a positive influence on the outflow rate from unemployment. Although the Hausman test always rejects the random effects model in favour of the fixed effects model, the impact of training on outflows from unemployment does not vary very much between the fixed and the random effects models. According to the estimation results without lagged dependent variables, it costs about $€ 300$ to $€ 500$ to reduce unemployment by one person through public training programmes. These estimates are much lower than those for the Czech and Slovak Republics. There, the numbers range between $€ 1,000$ and $€$ 3,500 (cf. Burda and Lubyova, 1995; Svejnar, Terrell, and Münich, 1995; Boeri and Burda, 1996).

In the specifications with lagged dependent variables (Table 4), the estimated costs get even smaller down to about $€ 200$ in the fixed effects specifications. The random effects models which estimate a cost around $€ 2,500$ are rejected by the Hausman test. As the lagged dependent variables are significant in all specifications, one may infer that the cost for getting an additional worker into employment through training is around $€ 200$. This estimate is fairly robust to the inclusion of current training expenditure amongst the set of regressors. However, as noted in Section 5, the estimates with lagged dependent variables may be biased. But even if we infer that the costs per outflow through training lie between $€ 300$ to $€ 500$, the conclusion will be that training is comparatively effective.

Given the short observation period, we do not test for structural stability over time. However, the persistent economic diversity of the Polish regions (Boeri 1994b; Kwiatkowski and Gawronska, 1995; Kwiatkowski and Kubiak, 1998; Steiner and Kwiatkowski, 1995) warrants to test for structural stability between types of regions. Following Boeri and Scarpetta (1995) and Burda and Profit (1996), we estimate the just presented regressions separately for modern, industrial, and agricultural voivodships, respectively. The geographical distribution of these groups of voivodships is depicted in the map of Figure 5 in the appendix. Regression results are presented in Table 5 to Table 10. Except in Table 5 and in the last equation of Table 9, the random effects model is rejected by the Hausman test.

As in our regressions for the whole of Poland, but unlike in Boeri and Scarpetta (1995), constant returns to scale are not rejected in the specifications without lagged dependent variables (Table 5, Table 7, and Table 9). Our coefficients on unemployment and vacancies for modern (diversified) and agricultural voivodships are similar to those found in Boeri and Scarpetta (1995) despite of their slightly different classification of the voivodships. In both cases, the coefficient on unemployment is around four times as large as the one on vacancies. However, for the industrial voivodships, the coefficients on the two 'inputs' for the matching process are about equal in Boeri and Scarpetta's (1995) regression, whereas we find 
the coefficient on unemployment to be about eleven times as large as the one on vacancies.

When lagged dependent variables are included in the equations, the hypothesis of constant returns to scale is rejected for all types of regions (see, Table 6, Table 8, and Table 10). We can thus substantiate the findings by Boeri and Burda (1996) and Burda and Profit (1996) that a dynamic specification of the matching function can make a decisive difference to the estimation results obtained. For modern voivodships (Table 6), the coefficients on the vacancy variable are positive again. Yet in the industrial voivodships, they are only marginally significantly different from zero. 
Table 5: Augmented Matching Function Estimates with Register Data without Lagged Dependent Variables - Modern Voivodships

\begin{tabular}{|c|c|c|c|c|c|c|c|c|}
\hline \multirow[t]{3}{*}{ Variable } & \multicolumn{4}{|c|}{ With current training expenditure } & \multicolumn{4}{|c|}{ Without current training expenditure } \\
\hline & \multicolumn{2}{|c|}{ Fixed effects } & \multicolumn{2}{|c|}{ Random effects } & \multicolumn{2}{|c|}{ Fixed effects } & \multicolumn{2}{|c|}{ Random effects } \\
\hline & Coeff. & $\mathrm{t}$-value & Coeff. & t-value & Coeff. & $\mathrm{t}$-value & Coeff. & t-value \\
\hline In unemployment $(\mathrm{t}-1)$ & 1.070 & 4.36 & 0.611 & 4.31 & 1.070 & 4.36 & 0.625 & 4.51 \\
\hline $\ln$ vacancies $(\mathrm{t}-1)$ & -0.017 & -0.21 & 0.175 & 2.96 & -0.028 & -0.36 & 0.176 & 2.99 \\
\hline Training expenditure & 0.081 & 0.97 & 0.056 & 0.58 & - & - & - & - \\
\hline Training exp. (t-1) & -0.064 & -0.66 & -0.097 & -0.84 & -0.020 & -0.23 & -0.058 & -0.62 \\
\hline Training exp.(t-2) & 0.087 & 0.89 & 0.046 & 0.39 & 0.085 & 0.87 & 0.048 & 0.41 \\
\hline Training exp.(t-3) & 0.101 & 1.19 & 0.072 & 0.70 & 0.098 & 1.16 & 0.075 & 0.74 \\
\hline IW expenditure & 0.123 & 2.69 & -0.012 & -0.31 & 0.121 & 2.65 & -0.017 & -0.42 \\
\hline PW expenditure & 0.054 & 1.07 & 0.002 & 0.03 & 0.052 & 1.04 & 0.000 & 0.00 \\
\hline Start-up loans exp. & 0.302 & 2.05 & -0.031 & -0.20 & 0.313 & 2.13 & -0.026 & -0.17 \\
\hline $\begin{array}{l}\text { Loans to enterprises } \\
\text { exp. }\end{array}$ & -0.035 & -0.32 & $-0.213^{*}$ & -1.80 & -0.001 & -0.01 & $-0.190^{*}$ & -1.72 \\
\hline \multicolumn{9}{|c|}{ (fixed time effects omitted) } \\
\hline Constant & -2.386 & -2.47 & -0.494 & -0.97 & -2.333 & -2.42 & -0.527 & -1.04 \\
\hline $\mathrm{R}^{2}$ overall & \multicolumn{2}{|c|}{0.417} & \multicolumn{2}{|c|}{0.787} & \multicolumn{2}{|c|}{0.400} & \multicolumn{2}{|c|}{0.786} \\
\hline$N_{i}$ & \multicolumn{2}{|c|}{8} & \multicolumn{2}{|c|}{8} & \multicolumn{2}{|c|}{8} & \multicolumn{2}{|c|}{8} \\
\hline$N_{t}$ & \multicolumn{2}{|c|}{13} & \multicolumn{2}{|c|}{13} & \multicolumn{2}{|c|}{13} & \multicolumn{2}{|c|}{13} \\
\hline $\mathrm{F} / \mathrm{LM}$ test & \multicolumn{2}{|c|}{0.000} & \multicolumn{2}{|c|}{0.147} & \multicolumn{2}{|c|}{0.000} & \multicolumn{2}{|c|}{0.166} \\
\hline Hausman test & \multicolumn{2}{|c|}{ - } & \multicolumn{2}{|c|}{0.610} & \multicolumn{2}{|c|}{-} & \multicolumn{2}{|c|}{0.425} \\
\hline CRS test & \multicolumn{2}{|c|}{0.824} & \multicolumn{2}{|c|}{0.058} & \multicolumn{2}{|c|}{0.861} & \multicolumn{2}{|c|}{0.069} \\
\hline Joint training test & \multicolumn{2}{|c|}{0.324} & \multicolumn{2}{|c|}{0.788} & & & & \\
\hline
\end{tabular}

Notes: shaded coefficients are significant at the 5 percent level; asterisked coefficients are significant at the 10 percent level;

IW: intervention works; PW: public works; CRS: constant returns to scale;

' $\mathrm{R}^{2}$ overall' (as Stata calls it) is the correlation between the actual and predicted outflows;

the null hypothesis of the F/LM test is the non-existence of voivodship-specific effects; test results are reported in terms of p-values, which means that the null hypothesis is rejected at the 5 percent significance level if the p-value is smaller than 0.05 ;

the null hypotheses are non-existence of voivodship-specific effects; equality of random and fixed effects estimates; constant returns to scale; all training variables equal to zero;

the time effects are modelled by quarterly dummies.

Source: Polish Ministry of Labour and Social Policy; own calculations. 
Table 6: Augmented Matching Function Estimates with Register Data with Lagged Dependent Variables - Modern Voivodships

\begin{tabular}{|c|c|c|c|c|c|c|c|c|}
\hline \multirow[t]{3}{*}{ Variable } & \multicolumn{4}{|c|}{ With current training expenditure } & \multicolumn{4}{|c|}{ Without current training expenditure } \\
\hline & \multicolumn{2}{|c|}{ Fixed Effects } & \multicolumn{2}{|c|}{ Random Effects } & \multicolumn{2}{|c|}{ Fixed Effects } & \multicolumn{2}{|c|}{ Random Effects } \\
\hline & Coeff. & $\mathrm{t}$-value & Coeff. & t-value & Coeff. & $\mathrm{t}$-value & Coeff. & $\mathrm{t}$-value \\
\hline $\ln$ outflows (t-1) & 0.448 & 4.33 & 0.520 & 4.65 & 0.443 & 4.347 & 0.522 & 4.715 \\
\hline $\ln$ outflows (t-2) & 0.216 & 2.79 & $0.168^{*}$ & 1.71 & 0.216 & 2.81 & $0.168^{*}$ & 1.72 \\
\hline $\ln$ outflows (t-3) & 0.106 & 1.29 & -0.097 & -1.01 & 0.106 & 1.31 & -0.098 & -1.03 \\
\hline $\ln$ outflows (t-4) & 0.200 & 2.80 & 0.044 & 0.58 & 0.195 & 2.80 & 0.046 & 0.62 \\
\hline In unemployment (t-1) & 2.719 & 6.90 & 0.406 & 2.95 & 2.692 & 7.01 & 0.411 & 3.08 \\
\hline In vacancies $(\mathrm{t}-1)$ & -0.162 & -2.21 & 0.003 & 0.05 & -0.158 & -2.20 & 0.003 & 0.04 \\
\hline Training expenditure & -0.026 & -0.35 & 0.015 & 0.16 & - & - & - & - \\
\hline Training exp. (t-1) & -0.029 & -0.36 & -0.095 & -0.94 & -0.044 & -0.63 & -0.085 & -1.07 \\
\hline Training exp.(t-2) & 0.063 & 0.78 & 0.090 & 0.89 & 0.064 & 0.80 & 0.091 & 0.90 \\
\hline Training exp.(t-3) & 0.046 & 0.66 & 0.009 & 0.10 & 0.047 & 0.68 & 0.009 & 0.11 \\
\hline IW expenditure & 0.027 & 0.62 & -0.004 & -0.12 & 0.029 & 0.67 & -0.005 & -0.15 \\
\hline PW expenditure & 0.035 & 0.79 & -0.054 & -1.03 & 0.036 & 0.81 & -0.055 & -1.06 \\
\hline Start-up loans exp. & -0.057 & -0.40 & -0.138 & -0.84 & -0.059 & -0.42 & -0.136 & -0.84 \\
\hline Loans to enterprises & 0.092 & 0.91 & 0.140 & 1.12 & 0.080 & 0.84 & 0.148 & 1.31 \\
\hline \multicolumn{9}{|c|}{ (fixed time effects omitted) } \\
\hline Constant & -10.551 & -6.08 & -0.769 & -1.53 & -10.438 & -6.16 & -0.787 & -1.62 \\
\hline $\mathrm{R}^{2}$ overall & \multicolumn{2}{|c|}{0.5731} & \multicolumn{2}{|c|}{0.8492} & \multicolumn{2}{|c|}{0.574} & \multicolumn{2}{|c|}{0.849} \\
\hline$N_{i}$ & \multicolumn{2}{|c|}{8} & \multicolumn{2}{|c|}{8} & \multicolumn{2}{|c|}{8} & \multicolumn{2}{|c|}{8} \\
\hline$N_{t}$ & \multicolumn{2}{|c|}{12} & \multicolumn{2}{|c|}{12} & \multicolumn{2}{|c|}{12} & \multicolumn{2}{|c|}{12} \\
\hline F/LM test & \multicolumn{2}{|c|}{0.000} & \multicolumn{2}{|c|}{0.303} & \multicolumn{2}{|c|}{0.000} & \multicolumn{2}{|c|}{0.301} \\
\hline Hausman test & \multicolumn{2}{|c|}{-} & \multicolumn{2}{|c|}{0.016} & \multicolumn{2}{|c|}{-} & \multicolumn{2}{|c|}{0.0001} \\
\hline CRS test & \multicolumn{2}{|c|}{0.000} & \multicolumn{2}{|c|}{0.710} & \multicolumn{2}{|c|}{0.000} & \multicolumn{2}{|c|}{0.655} \\
\hline Joint training test & & & & & & & & \\
\hline
\end{tabular}

Notes: shaded coefficients are significant at the 5 percent level; asterisked coefficients are significant at the 10 percent level; IW: intervention works; PW: public works; CRS: constant returns to scale; ' $\mathrm{R}^{2}$ overall' (as Stata calls it) is the correlation between the actual and predicted outflows;

the null hypothesis of the F/LM test is the non-existence of voivodship-specific effects; test results are reported in terms of p-values, which means that the null hypothesis is rejected at the 5 percent significance level if the p-value is smaller than 0.05 ;

the null hypotheses are non-existence of voivodship-specific effects; equality of random and fixed effects estimates; constant returns to scale; all training variables equal to zero;

the time effects are modelled by quarterly dummies.

Source: Polish Ministry of Labour and Social Policy; own calculations. 
Table 7: Augmented Matching Function Estimates with Register Data without Lagged Dependent Variables - Industrial Voivodships

\begin{tabular}{|c|c|c|c|c|c|c|c|c|}
\hline \multirow[t]{3}{*}{ Variable } & \multicolumn{4}{|c|}{ With current training expenditure } & \multicolumn{4}{|c|}{ Without current training expenditure } \\
\hline & \multicolumn{2}{|c|}{ Fixed Effects } & \multicolumn{2}{|c|}{ Random Effects } & \multicolumn{2}{|c|}{ Fixed Effects } & \multicolumn{2}{|c|}{ Random Effects } \\
\hline & Coeff. & t-value & Coeff. & t-value & Coeff. & t-value & Coeff. & t-value \\
\hline In unemployment (t-1) & 1.111 & 5.10 & 0.697 & 7.32 & 0.981 & 4.53 & 0.708 & 6.93 \\
\hline $\ln$ vacancies $(\mathrm{t}-1)$ & 0.098 & 2.07 & 0.179 & 4.19 & $0.080^{*}$ & 1.67 & 0.146 & 3.43 \\
\hline Training expenditure & -0.116 & -2.81 & -0.047 & -1.20 & - & - & - & - \\
\hline Training exp. (t-1) & 0.065 & 2.02 & 0.072 & 2.17 & 0.050 & 1.533 & $0.058^{*}$ & 1.85 \\
\hline Training exp.(t-2) & $-0.059^{*}$ & -1.82 & -0.034 & -1.03 & -0.049 & -1.50 & -0.037 & -1.14 \\
\hline Training exp.(t-3) & -0.007 & -0.21 & 0.044 & 1.39 & 0.027 & 0.86 & 0.046 & 1.53 \\
\hline IW expenditure & -0.063 & -2.34 & -0.060 & -2.30 & -0.086 & -3.28 & -0.075 & -3.04 \\
\hline PW expenditure & 0.078 & 3.86 & 0.029 & 1.57 & 0.077 & 3.72 & 0.043 & 2.27 \\
\hline Start-up loans exp. & 0.174 & 4.56 & 0.192 & 4.88 & 0.162 & 4.21 & 0.178 & 4.66 \\
\hline $\begin{array}{l}\text { Loans to enterprises } \\
\text { exp. }\end{array}$ & 0.025 & 0.72 & 0.007 & 0.21 & -0.003 & -0.08 & -0.004 & -0.12 \\
\hline \multicolumn{9}{|c|}{ (fixed time effects omitted) } \\
\hline Constant & -2.484 & -2.80 & -0.929 & -2.56 & -1.996 & -2.25 & -0.957 & -2.43 \\
\hline $\mathrm{R}^{2}$ overall & \multicolumn{2}{|c|}{0.853} & \multicolumn{2}{|c|}{0.860} & \multicolumn{2}{|c|}{0.806} & \multicolumn{2}{|c|}{0.854} \\
\hline$N_{i}$ & \multicolumn{2}{|c|}{17} & \multicolumn{2}{|c|}{17} & \multicolumn{2}{|c|}{17} & \multicolumn{2}{|c|}{17} \\
\hline$N_{t}$ & \multicolumn{2}{|c|}{13} & \multicolumn{2}{|c|}{13} & \multicolumn{2}{|c|}{13} & \multicolumn{2}{|c|}{13} \\
\hline $\mathrm{F} / \mathrm{LM}$ test & \multicolumn{2}{|c|}{0.000} & \multicolumn{2}{|c|}{0.000} & \multicolumn{2}{|c|}{0.000} & \multicolumn{2}{|c|}{0.000} \\
\hline Hausman test & \multicolumn{2}{|c|}{ - } & \multicolumn{2}{|c|}{0.0202} & \multicolumn{2}{|c|}{-} & \multicolumn{2}{|c|}{0.472} \\
\hline CRS test & \multicolumn{2}{|c|}{0.348} & \multicolumn{2}{|c|}{0.165} & \multicolumn{2}{|c|}{0.782} & \multicolumn{2}{|c|}{0.120} \\
\hline Joint training test & \multicolumn{2}{|c|}{0.020} & & & & & & \\
\hline Costs in PLZ & & & & & & & & \\
\hline Costs in $€$ & & & & & & & & \\
\hline
\end{tabular}

Notes: shaded coefficients are significant at the 5 percent level; asterisked coefficients are significant at the 10 percent level;

IW: intervention works; PW: public works; CRS: constant returns to scale;

' $\mathrm{R}^{2}$ overall' (as Stata calls it) is the correlation between the actual and predicted outflows;

the null hypothesis of the F/LM test is the non-existence of voivodship-specific effects; test results are reported in terms of p-values, which means that the null hypothesis is rejected at the 5 percent significance level if the p-value is smaller than 0.05 ;

the null hypotheses are non-existence of voivodship-specific effects; equality of random and fixed effects estimates; constant returns to scale; all training variables equal to zero;

the costs in PLZ and costs in $€$ are the estimated costs to increase the outflow from unemployment by one person (at the mean);

the time effects are modelled by quarterly dummies.

Source: Polish Ministry of Labour and Social Policy; own calculations. 
Table 8: Augmented Matching Function Estimates with Register Data with Lagged Dependent Variables - Industrial Voivodships

\begin{tabular}{|c|c|c|c|c|c|c|c|c|}
\hline \multirow[t]{3}{*}{ Variable } & \multicolumn{4}{|c|}{ With current training expenditure } & \multicolumn{4}{|c|}{ Without current training expenditure } \\
\hline & \multicolumn{2}{|c|}{ Fixed effects } & \multicolumn{2}{|c|}{ Random effects } & \multicolumn{2}{|c|}{ Fixed effects } & \multicolumn{2}{|c|}{ Random effects } \\
\hline & Coeff. & t-value & Coeff. & t-value & Coeff. & t-value & Coeff. & t-value \\
\hline $\ln$ outflows (t-1) & 0.256 & 3.74 & 0.375 & 5.94 & 0.265 & 3.83 & 0.372 & 5.92 \\
\hline $\ln$ outflows $(\mathrm{t}-2)$ & 0.022 & 0.37 & 0.067 & 1.12 & 0.052 & 0.90 & 0.075 & 1.28 \\
\hline $\ln$ outflows (t-3) & -0.002 & -0.04 & 0.020 & 0.38 & -0.004 & -0.08 & 0.016 & 0.30 \\
\hline $\ln$ outflows (t-4) & 0.108 & 2.75 & 0.118 & 3.10 & 0.104 & 2.64 & 0.115 & 3.05 \\
\hline In unemployment (t-1) & 1.218 & 4.81 & 0.316 & 5.78 & 1.117 & 4.45 & 0.313 & 5.75 \\
\hline In vacancies (t-1) & $0.085^{*}$ & 1.75 & 0.102 & 3.15 & 0.073 & 1.49 & 0.099 & 3.09 \\
\hline Training expenditure & -0.091 & -2.07 & -0.025 & -0.69 & - & - & - & - \\
\hline Training exp. (t-1) & 0.073 & 2.05 & 0.079 & 2.26 & 0.053 & 1.53 & 0.066 & 2.25 \\
\hline Training exp.(t-2) & -0.080 & -2.44 & -0.081 & -2.54 & -0.074 & -2.24 & -0.083 & -2.60 \\
\hline Training exp.(t-3) & 0.017 & 0.51 & 0.056 & 2.02 & 0.043 & 1.41 & 0.058 & 2.09 \\
\hline IW expenditure & -0.032 & -1.13 & -0.032 & -1.54 & $-0.045^{*}$ & -1.65 & $-0.036^{*}$ & -1.82 \\
\hline PW expenditure & 0.043 & 1.96 & 0.002 & 0.13 & $0.037^{*}$ & 1.67 & 0.003 & 0.25 \\
\hline Start-up loans exp. & 0.070 & 1.11 & 0.027 & 0.45 & 0.069 & 1.09 & 0.025 & 0.41 \\
\hline $\begin{array}{l}\text { Loans to enterprises } \\
\text { exp. }\end{array}$ & -0.009 & -0.26 & -0.036 & -1.08 & -0.031 & -0.91 & -0.044 & -1.37 \\
\hline \multicolumn{9}{|c|}{ (fixed time effects omitted) } \\
\hline Constant & -3.969 & -3.71 & -0.711 & -3.79 & -3.639 & -3.40 & -0.690 & -3.74 \\
\hline $\mathrm{R}^{2}$ overall & \multicolumn{2}{|c|}{0.8312} & \multicolumn{2}{|c|}{0.9307} & \multicolumn{2}{|c|}{0.845} & \multicolumn{2}{|c|}{0.931} \\
\hline$N_{i}$ & \multicolumn{2}{|c|}{17} & \multicolumn{2}{|c|}{17} & \multicolumn{2}{|c|}{17} & \multicolumn{2}{|c|}{17} \\
\hline$N_{t}$ & \multicolumn{2}{|c|}{12} & \multicolumn{2}{|c|}{12} & \multicolumn{2}{|c|}{12} & \multicolumn{2}{|c|}{12} \\
\hline $\mathrm{F} / \mathrm{LM}$ test & \multicolumn{2}{|c|}{0.008} & \multicolumn{2}{|c|}{0.389} & \multicolumn{2}{|c|}{0.024} & \multicolumn{2}{|c|}{0.393} \\
\hline Hausman test & \multicolumn{2}{|c|}{-} & \multicolumn{2}{|c|}{0.021} & \multicolumn{2}{|c|}{-} & \multicolumn{2}{|c|}{0.079} \\
\hline CRS test & \multicolumn{2}{|c|}{0.014} & \multicolumn{2}{|c|}{0.959} & \multicolumn{2}{|c|}{0.030} & & \\
\hline Joint training test & & & & & & & & \\
\hline Costs in PLZ & & & & & & & & \\
\hline Costs in $€$ & & & & & & & & \\
\hline
\end{tabular}

Notes: shaded coefficients are significant at the 5 percent level; asterisked coefficients are significant at the 10 percent level; IW: intervention works; PW: public works; CRS: constant returns to scale; 'R ${ }^{2}$ overall' (as Stata calls it) is the correlation between the actual and the predicted outflows;

the null hypothesis of the F/LM test is the non-existence of voivodship-specific effects; test results are reported in terms of p-values, which means that the null hypothesis is rejected at the 5 percent significance level if the p-value is smaller than 0.05 ; the null hypotheses are non-existence of voivodship-specific effects; equality of random and fixed effects estimates; constant returns to scale; all training variables equal to zero;

the costs in PLZ and costs in $€$ are the estimated costs to increase the outflow from unemployment by one person (at the mean); the time effects are modelled by quarterly dummies.

Source: Polish Ministry of Labour and Social Policy; own calculations. 
Table 9: Augmented Matching Function Estimates with Register Data without Lagged Dependent Variables - Agricultural Voivodships

\begin{tabular}{|c|c|c|c|c|c|c|c|c|}
\hline \multirow[t]{3}{*}{ Variable } & \multicolumn{4}{|c|}{ With current training expenditure } & \multicolumn{4}{|c|}{ Without current training expenditure } \\
\hline & \multicolumn{2}{|c|}{ Fixed effects } & \multicolumn{2}{|c|}{ Random effects } & \multicolumn{2}{|c|}{ Fixed effects } & \multicolumn{2}{|c|}{ Random effects } \\
\hline & Coeff. & $\mathrm{t}$-value & Coeff. & $\mathrm{t}$-value & Coeff. & $\mathrm{t}$-value & Coeff. & $\mathrm{t}$-value \\
\hline In unemployment (t-1) & 0.803 & 3.57 & 0.628 & 11.84 & 0.811 & 3.62 & 0.614 & 9.53 \\
\hline $\ln$ vacancies $(\mathrm{t}-1)$ & 0.182 & 3.88 & 0.179 & 5.46 & 0.182 & 3.88 & 0.176 & 4.81 \\
\hline Training expenditure & 0.067 & 0.61 & -0.033 & -0.30 & - & - & - & - \\
\hline Training exp. (t-1) & $0.215^{*}$ & 1.68 & 0.160 & 1.18 & 0.253 & 2.24 & $0.183^{*}$ & 1.66 \\
\hline Training exp.(t-2) & -0.091 & -0.71 & -0.092 & -0.68 & -0.102 & -0.81 & -0.094 & -0.73 \\
\hline Training exp.(t-3) & 0.124 & 1.11 & 0.007 & 0.06 & 0.118 & 1.06 & 0.048 & 0.44 \\
\hline IW expenditure & -0.004 & -0.07 & 0.049 & 1.20 & 0.001 & 0.02 & 0.032 & 0.73 \\
\hline PW expenditure & 0.025 & 0.60 & -0.013 & -0.42 & 0.023 & 0.54 & -0.008 & -0.23 \\
\hline Start-up loans exp. & 0.381 & 2.58 & 0.108 & 0.77 & 0.375 & 2.55 & 0.209 & 1.50 \\
\hline $\begin{array}{l}\text { Loans to enterprises } \\
\text { exp. }\end{array}$ & -0.218 & -1.32 & -0.178 & -1.06 & -0.203 & -1.25 & -0.183 & -1.13 \\
\hline \multicolumn{9}{|c|}{ (fixed time effects omitted) } \\
\hline Constant & $-1.468^{*}$ & -1.83 & -0.752 & -4.17 & $-1.482^{*}$ & -1.85 & -0.735 & -3.30 \\
\hline $\mathrm{R}^{2}$ overall & \multicolumn{2}{|c|}{0.797} & \multicolumn{2}{|c|}{0.824} & \multicolumn{2}{|c|}{0.799} & \multicolumn{2}{|c|}{0.8216} \\
\hline$N_{i}$ & \multicolumn{2}{|c|}{20} & \multicolumn{2}{|c|}{20} & \multicolumn{2}{|c|}{20} & \multicolumn{2}{|c|}{20} \\
\hline$N_{t}$ & \multicolumn{2}{|c|}{13} & \multicolumn{2}{|c|}{13} & \multicolumn{2}{|c|}{13} & \multicolumn{2}{|c|}{13} \\
\hline F/LM test & \multicolumn{2}{|c|}{0.000} & \multicolumn{2}{|c|}{0.000} & \multicolumn{2}{|c|}{0.000} & \multicolumn{2}{|c|}{0.000} \\
\hline Hausman test & \multicolumn{2}{|c|}{ - } & \multicolumn{2}{|c|}{0.001} & \multicolumn{2}{|c|}{-} & \multicolumn{2}{|c|}{0.259} \\
\hline CRS test & \multicolumn{2}{|c|}{0.951} & \multicolumn{2}{|c|}{0.001} & \multicolumn{2}{|c|}{0.979} & \multicolumn{2}{|c|}{0.002} \\
\hline Joint training test & \multicolumn{2}{|c|}{0.177} & & & & & & \\
\hline Costs in PLZ & & & & & & & & \\
\hline Costs in $€$ & & & & & & & & \\
\hline
\end{tabular}

Notes: shaded coefficients are significant at the 5 percent level; asterisked coefficients are significant at the 10 percent level;

IW: intervention works; PW: public works; CRS: constant returns to scale;

' $\mathrm{R}^{2}$ overall' (as Stata calls it) is the correlation between the actual and the predicted outflows;

the null hypothesis of the F/LM test is the non-existence of voivodship-specific effects; test results are reported in terms of p-values, which means that the null hypothesis is rejected at the 5 percent significance level if the p-value is smaller than 0.05 ;

the null hypotheses are non-existence of voivodship-specific effects; equality of random and fixed effects estimates; constant returns to scale; all training variables equal to zero;

the costs in PLZ and costs in $€$ are the estimated costs to increase the outflow from unemployment by one person (at the mean);

the time effects are modelled by quarterly dummies.

Source: Polish Ministry of Labour and Social Policy; own calculations. 
Table 10: Augmented Matching Function Estimates with Register Data with Lagged Dependent Variables - Agricultural Voivodships

\begin{tabular}{|c|c|c|c|c|c|c|c|c|}
\hline \multirow[t]{3}{*}{ Variable } & \multicolumn{4}{|c|}{ With current training expenditure } & \multicolumn{4}{|c|}{ Without current training expenditure } \\
\hline & \multicolumn{2}{|c|}{ Fixed effects } & \multicolumn{2}{|c|}{ Random effects } & \multicolumn{2}{|c|}{ Fixed effects } & \multicolumn{2}{|c|}{ Random effects } \\
\hline & Coeff. & t-value & Coeff. & t-value & Coeff. & t-value & Coeff. & t-value \\
\hline $\ln$ outflows (t-1) & 0.257 & 3.60 & 0.301 & 4.89 & 0.260 & 3.63 & 0.301 & 4.89 \\
\hline In outflows (t-2) & $0.122^{*}$ & 1.93 & 0.119 & 2.03 & $0.115^{*}$ & 1.82 & $0.114^{*}$ & 1.96 \\
\hline $\ln$ outflows (t-3) & 0.006 & -0.12 & -0.011 & -0.24 & -0.003 & -0.06 & -0.010 & -0.21 \\
\hline $\ln$ outflows (t-4) & 0.171 & 3.99 & 0.168 & 4.30 & 0.171 & 3.98 & 0.169 & 4.31 \\
\hline In unemployment (t-1) & 1.311 & 4.87 & 0.351 & 6.10 & 1.336 & 4.96 & 0.359 & 6.32 \\
\hline In vacancies (t-1) & 0.105 & 2.10 & 0.050 & 1.62 & 0.106 & 2.11 & $0.051^{*}$ & 1.66 \\
\hline Training expenditure & 0.152 & 1.41 & 0.079 & 0.75 & - & - & - & - \\
\hline Training exp. (t-1) & 0.133 & 1.11 & 0.092 & 0.74 & 0.219 & 2.11 & 0.147 & 1.47 \\
\hline Training exp.(t-2) & -0.097 & -0.82 & -0.116 & -0.94 & -0.124 & -1.06 & -0.129 & -1.06 \\
\hline Training exp.(t-3) & 0.066 & 0.64 & -0.054 & -0.54 & 0.051 & 0.50 & -0.052 & -0.53 \\
\hline IW expenditure & 0.046 & -0.84 & 0.012 & 0.36 & -0.038 & -0.70 & 0.013 & 0.37 \\
\hline PW expenditure & 0.025 & 0.62 & -0.033 & -1.27 & 0.020 & 0.49 & -0.033 & -1.27 \\
\hline Start-up loans exp. & 0.518 & 3.40 & $0.242^{*}$ & 1.73 & 0.505 & 3.31 & $0.244^{*}$ & 1.75 \\
\hline $\begin{array}{l}\text { Loans to enterprises } \\
\text { exp. }\end{array}$ & 0.207 & -1.08 & -0.156 & -0.83 & -0.197 & -1.03 & -0.147 & -0.79 \\
\hline \multicolumn{9}{|c|}{ (fixed time effects omitted) } \\
\hline Constant & -4.287 & -4.09 & -0.897 & -5.76 & -4.358 & -4.15 & -0.913 & -5.93 \\
\hline $\mathrm{R}^{2}$ overall & \multicolumn{2}{|c|}{0.7429} & \multicolumn{2}{|c|}{0.8758} & \multicolumn{2}{|c|}{0.743} & \multicolumn{2}{|c|}{0.876} \\
\hline$N_{i}$ & \multicolumn{2}{|c|}{20} & \multicolumn{2}{|c|}{20} & \multicolumn{2}{|c|}{20} & \multicolumn{2}{|c|}{20} \\
\hline$N_{t}$ & \multicolumn{2}{|c|}{12} & \multicolumn{2}{|c|}{12} & \multicolumn{2}{|c|}{12} & \multicolumn{2}{|c|}{12} \\
\hline $\mathrm{F} / \mathrm{LM}$ test & \multicolumn{2}{|c|}{0.006} & \multicolumn{2}{|c|}{0.383} & \multicolumn{2}{|c|}{0.010} & \multicolumn{2}{|c|}{0.3671} \\
\hline Hausman test & \multicolumn{2}{|c|}{-} & \multicolumn{2}{|c|}{0.002} & \multicolumn{2}{|c|}{-} & \multicolumn{2}{|c|}{0.002} \\
\hline CRS test & \multicolumn{2}{|c|}{0.007} & \multicolumn{2}{|c|}{0.660} & \multicolumn{2}{|c|}{0.0054} & & \\
\hline Joint training test & & & & & & & & \\
\hline Costs in PLZ & & & & & & & & \\
\hline Costs in $€$ & & & & & & & & \\
\hline
\end{tabular}

Notes: shaded coefficients are significant at the 5 percent level; asterisked coefficients are significant at the 10 percent level; IW: intervention works; PW: public works; CRS: constant returns to scale; ' $\mathrm{R}^{2}$ overall' (as Stata calls it) is the correlation between the actual and the predicted outflows;

the null hypothesis of the F/LM test is the non-existence of voivodship-specific effects; test results are reported in terms of p-values, which means that the null hypothesis is rejected at the 5 percent significance level if the p-value is smaller than 0.05 ; the null hypotheses are non-existence of voivodship-specific effects; equality of random and fixed effects estimates; constant returns to scale; all training variables equal to zero;

the costs in PLZ and costs in $€$ are the estimated costs to increase the outflow from unemployment by one person (at the mean); the time effects are modelled by quarterly dummies.

Source: Polish Ministry of Labour and Social Policy; own calculations. 
There is also a difference in the estimated effects of training between the three types of regions. The joint test on the training variables suggests that there are no effects of training expenditure on the outflows from unemployment in the modern voivodships.

For the industrial voivodships, the estimates are rather sensitive with respect to the model specification. When current expenditure on training is included as a regressor, the fixed effects model estimates a negative training effect, irrespective of whether lagged dependent variables are included or not. Potential endogeneity problems on the one hand, and time lags until training expenditure becomes effective on the other, are reasons why one might want to leave out current training expenditure from the set of regressors. We have seen in Table 3 and Table 4, that the inclusion of current training expenditure does not make a real difference to the estimation results for the whole of Poland. However, for the industrial voivodships (Table 7 and Table 8), the inclusion of current training expenditure of the estimates becomes decisive. The estimates with current training expenditure suggest that on average, every $€ 300$ spent on training programmes reduce the outflows from unemployment by one person. By contrast, the estimates without current training expenditure reveal that training can increase the number of outflows from unemployment. The estimated cost to reduce unemployment by one person through training varies between $€ 500$ (random effects model without lagged dependent variables in Table 7) and $€ 900$ (fixed effect model with lagged dependent variables in Table 8).

In the agricultural voivodships, the training variables are jointly (but not necessarily individually) insignificant even at the 10 percent level in all specifications. Only if one is willing to accept statistical significance at lower levels, positive training effects can be detected. Indeed, the point estimates in the fixed effects models with lagged dependent variables in Table 10 are rather astonishing. They would suggest that reducing unemployment by one person in the agricultural voivodships only costs between $€ 60$ and $€ 110$. Although we know that these estimates may be biased due to the inclusion of lagged dependent variables ( $c f$. Section 5), the specifications without lagged dependent variables lead to similar conclusions. At the 12 percent significance level, the fixed effects model without current training expenditure in Table 9 estimates the costs of and additional outflow to be $€ 130$. In the corresponding random effects specification, the estimated costs are higher $(€ 260$, which is still low), but insignificant.

McCloskey and Ziliak (1996) argue that econometricians should not exclusively focus on the statistical significance of the variables in their models, but concentrate on what is economically significant. The estimates for the agricultural voivodships are a good example for the potential conflict between the two concepts of significance: at standard levels of statistical significance, training has no effects at 
all. However, the 5 or 10 percent significance level, albeit common practice, are arbitrary thresholds for the rejection of a null hypothesis. The point estimates of the costs to reduce unemployment in the agricultural areas of Poland through training programmes are very low. Hence they are of high economic significance. It has to be left to the reader whether he or she is willing to accept estimates which are only safe at a 12 percent significance level or lower.

We have not reported the training effects for modern voivodships in euro. In the modern areas of Poland, the training variables are not even significantly different from zero at the 50(!) percent significance level (if one ignores the fixed effect estimates of Table 5, which are not efficient according to the Hausman test statistics). We therefore believe that the training variables cannot be given a positive interpretation for the modern voivodships.

Table 11 shows that the differences in the estimated training effects between the modern, industrialised, and agricultural voivodships are not very sharp. We have estimated joint regressions for pairs of two regions. In addition to the set of regressors used above, we have included either all or only the training variables multiplied by a dummy variable with value one for the second region and zero otherwise. We then use the test on the joint significance of these compound variables as a test on the equality of the coefficients between the two regions in question. A plus sign in Table 11 signifies that the coefficients are statistically different at least at the 10 percent level between the two regions. A minus sign stands for no statistical difference.

It is shown that the matching functions as a whole differ between modern and industrialised regions on the one hand, and modern and agricultural regions on the other. The matching functions for the industrialised and agricultural regions do not seem to be statistically distinguishable from each other. If one restricts the matching functions between the regions to be equal in all respects except the training coefficients, one does at least for the specifications without lagged dependent variables hardly observe any difference in the training effect between the regions. These test results suggest that the above-reported differences in the training effects between the modern, industrialised, and agricultural voivodships might be exaggerated. In particular, we cannot say that the training effect differs significantly between the industrialised and agricultural voivodships.

We have also classified the voivodships into groups of high, medium, and low unemployment regions as shown in Figure 4 in the appendix. The estimation results for these subgroups are not reported here, but available from the author upon request. Instead, we report the test results for the equality of coefficients between these subgroups in Table 12. As the table shows, there are no significant differences between these types of regions. This is valid for both the tests on all coefficients of the matching function as well as the tests on the training coefficient only. 
Table 11: Tests of the Equality of Coefficients between Modern, Industrial, and Agricultural Voivodships

\begin{tabular}{|c|c|c|c|c|c|c|c|c|}
\hline \multirow[t]{3}{*}{ Test } & \multicolumn{4}{|c|}{ Without lagged dependent variables } & \multicolumn{4}{|c|}{ With lagged dependent variables } \\
\hline & \multicolumn{2}{|c|}{$\begin{array}{l}\text { With current } \\
\text { training }\end{array}$} & \multicolumn{2}{|c|}{$\begin{array}{l}\text { Without current } \\
\text { training }\end{array}$} & \multicolumn{2}{|c|}{ With current training } & \multicolumn{2}{|c|}{$\begin{array}{l}\text { Without current } \\
\text { training }\end{array}$} \\
\hline & $\mathrm{FE}$ & $\mathrm{RE}$ & FE & RE & FE & RE & $\mathrm{FE}$ & $\mathrm{RE}$ \\
\hline
\end{tabular}

Test of the equality of all coefficients

\begin{tabular}{l|c|c|c|c|c|c|c|c|} 
Modern-industrialised & + & $(+)$ & - & $(+)$ & + & + & + & + \\
Modern-agricultural & $(+)$ & + & $(+)$ & + & + & + & + & + \\
Industrialised-agric. & - & - & - & - & - & - & - & - \\
\hline
\end{tabular}

Test of the equality of the training coefficients - all other coefficients restricted to be equal between regions

\begin{tabular}{l|c|c|c|c|c|c|c|c} 
Modern-industrialised & + & + & $(+)$ & + & $(-)$ & - & $(-)$ & - \\
Modern-agricultural & - & - & - & - & - & - & - & - \\
Industrialised-agric. & + & - & - & - & + & $(-)$ & - & $(-)$ \\
\hline \hline
\end{tabular}

Notes: FE: fixed effects; RE: random effects;

' + ' means that the coefficients are significantly different between the specified types of regions at the 5 percent level; '(+)', '(-)', and '- 'signify that the coefficients are different at the 10 percent level, just not different at the 10 percent level, and not significantly different, respectively.

Source: Polish Ministry of Labour and Social Policy; own calculations.

Table 12: Tests of the Equality of Coefficients between High, Medium and Low Unemployment Voivodships

\begin{tabular}{l|c|c|c|c|c|c|c|c}
\hline \hline Test & \multicolumn{3}{|c|}{ Without lagged dependent variables } & \multicolumn{3}{c}{ With lagged dependent variables } \\
& With current training & Without current & With current training & \multicolumn{2}{c}{$\begin{array}{c}\text { Without current } \\
\text { training }\end{array}$} \\
& $\mathrm{FE}$ & $\mathrm{RE}$ & $\mathrm{FE}$ & $\mathrm{RE}$ & $\mathrm{FE}$ & $\mathrm{RE}$ & $\mathrm{FE}$ & $\mathrm{RE}$ \\
\hline
\end{tabular}

Test of the equality of the training coefficients - all other coefficients restricted to be equal between regions

Low U-medium U

Low U-high U

Medium U-high U

Note: FE: fixed effects; RE: random effects; U: unemployment.

' + ' would mean that the coefficients are significantly different between the specified types of regions at the 5 percent level; '(+)', '(-)', and '-' signify that the coefficients are different at the 10 percent level, just not different at the 10 percent level, and not significantly different, respectively.

Source: Polish Ministry of Labour and Social Policy; own calculations. 


\section{Estimates Based on Polish Labour Force Survey Data}

Table 13 and Table 14 report the estimation results for the whole of Poland where the outflow from unemployment and the stock of the unemployed variables are taken from the Polish Labour Force Survey (PLFS). In contrast to the estimates from the register data (Table 3), the Hausman test does not reject the random effects model in the specifications without lagged dependent variables (Table 13). Including lagged dependent variables leads to a rejection, though (Table 14). Constant returns to scale are generally rejected in favour of decreasing returns, in contrast to our results based on the register data, where we have found constant or increasing returns (Table 3 and Table 4). However, decreasing returns have been found in the previous studies on Poland which have carried out tests on the issue (Boeri, 1994a; Boeri and Scarpetta, 1995).

An interesting finding arises from the comparison between the results with lagged dependent variables in the two data sets (Table 4 and Table 14). The estimated longrun elasticity of outflows with respect to unemployment is much smaller when using labour force survey (PLFS) data than when using register data. Indeed, the significance of the unemployment variable is even called into question from the PLFS data. Our estimation results suggest that the registered unemployed have a higher search effectiveness than the unemployed according to the ILO criteria (not working, looking for work, ready to start work). This finding is consistent with the hypothesis that there are many people on the register who draw unemployment benefits until their entitlement to benefits runs out and then find a job fairly quickly. As the unemployment entitlement period generally lasts 12 months in Poland, one may expect that, on the other hand, many long-term unemployed persons drop off the register after that period and look for jobs through different channels (Boeri, 1994a). If this was true, then the registered unemployed would have a lower longterm unemployment share than the unemployed according to the ILO definition in the PLFS. That the two definitions of unemployment lead to rather distinct unemployment populations has already been demonstrated in Figure 1 on page 11. There it is shown that the number of unemployed according to the ILO definition has a much greater cyclical component than the number of registered unemployed people.

For our purposes, the most important finding from the regressions in Table 13 and Table 14 is that the training variables become insignificant at the 5 percent level in all specifications. The insignificance of the training variables is a robust result for the PLFS data: like with the register data, we have also estimated separate regressions for modern, industrial, agricultural, and low, medium, and high unemployment voivodships. In none of the regressions were the training variables significant. The results are not reported here, but can be obtained from the author upon request. 
Table 13: Augmented Matching Function Estimates with PLFS Data without Lagged Dependent Variables

\begin{tabular}{|c|c|c|c|c|c|c|c|c|}
\hline \multirow[t]{3}{*}{ Variable } & \multicolumn{4}{|c|}{ With current training expenditure } & \multicolumn{4}{|c|}{ Without current training expenditure } \\
\hline & \multicolumn{2}{|c|}{ Fixed effects } & \multicolumn{2}{|c|}{ Random effects } & \multicolumn{2}{|c|}{ Fixed effects } & \multicolumn{2}{|c|}{ Random effects } \\
\hline & Coeff. & $\mathrm{t}$-value & Coeff. & t-value & Coeff. & $\mathrm{t}$-value & Coeff. & t-value \\
\hline In unemployment $(\mathrm{t}-1)$ & 0.213 & 1.368 & 0.600 & 6.09 & 0.218 & 1.40 & 0.574 & 5.71 \\
\hline $\ln$ vacancies $(\mathrm{t}-1)$ & 0.253 & 2.785 & 0.229 & 3.74 & 0.260 & 2.86 & 0.231 & 3.71 \\
\hline Training expenditure & $-0.198^{*}$ & -1.669 & -0.107 & -1.04 & - & - & - & - \\
\hline Training exp. (t-1) & 0.103 & 0.946 & 0.138 & 1.33 & 0.048 & 0.46 & 0.085 & 0.93 \\
\hline Training exp.(t-2) & 0.008 & 0.074 & 0.027 & 0.26 & 0.017 & 0.16 & 0.020 & 0.20 \\
\hline Training exp.(t-3) & -0.138 & -1.359 & -0.070 & -0.78 & -0.094 & -0.96 & -0.066 & -0.73 \\
\hline IW expenditure & -0.026 & -0.400 & -0.017 & -0.33 & -0.042 & -0.65 & -0.023 & -0.45 \\
\hline PW expenditure & -0.051 & -0.898 & -0.063 & -1.44 & -0.055 & -0.97 & -0.058 & -1.31 \\
\hline Start-up loans exp. & -0.058 & -0.445 & -0.011 & -0.09 & -0.093 & -0.73 & -0.047 & -0.40 \\
\hline $\begin{array}{l}\text { Loans to enterprises } \\
\text { exp. }\end{array}$ & 0.161 & 1.346 & 0.135 & 1.21 & 0.107 & 0.93 & 0.101 & 0.96 \\
\hline \multicolumn{9}{|c|}{ (fixed time effects omitted) } \\
\hline Constant & 1.531 & 2.389 & -0.096 & -0.26 & 1.438 & 2.25 & -0.019 & -0.05 \\
\hline $\mathrm{R}^{2}$ overall & \multicolumn{2}{|c|}{0.340} & \multicolumn{2}{|c|}{0.431} & \multicolumn{2}{|c|}{0.378} & \multicolumn{2}{|c|}{0.430} \\
\hline$N_{i}$ & \multicolumn{2}{|c|}{49} & \multicolumn{2}{|c|}{49} & \multicolumn{2}{|c|}{49} & \multicolumn{2}{|c|}{49} \\
\hline $\bar{N}_{t}$ & \multicolumn{2}{|c|}{12.71} & \multicolumn{2}{|c|}{12.68} & \multicolumn{2}{|c|}{12.71} & \multicolumn{2}{|c|}{12.68} \\
\hline $\mathrm{F} / \mathrm{LM}$ test & \multicolumn{2}{|c|}{0.000} & \multicolumn{2}{|c|}{0.000} & \multicolumn{2}{|c|}{0.000} & \multicolumn{2}{|c|}{0.000} \\
\hline Hausman test & \multicolumn{2}{|c|}{-} & \multicolumn{2}{|c|}{0.813} & \multicolumn{2}{|c|}{-} & \multicolumn{2}{|c|}{0.933} \\
\hline CRS test & \multicolumn{2}{|c|}{0.002} & \multicolumn{2}{|c|}{0.030} & \multicolumn{2}{|c|}{0.003} & \multicolumn{2}{|c|}{0.015} \\
\hline Joint training test & \multicolumn{2}{|c|}{0.392} & \multicolumn{2}{|c|}{0.629} & & & & \\
\hline
\end{tabular}

Notes: shaded coefficients are significant at the 5 percent level; asterisked coefficients are significant at the 10 percent level;

IW: intervention works; PW: public works; CRS: constant returns to scale;

' $\mathrm{R}^{2}$ overall' (as Stata calls it) is the correlation between the actual and the predicted outflows;

the null hypothesis of the F/LM test is the non-existence of voivodship-specific effects; test results are reported in terms of p-values, which means that the null hypothesis is rejected at the 5 percent significance level if the p-value is smaller than 0.05 ;

the null hypotheses are non-existence of voivodship-specific effects; equality of random and fixed effects estimates; constant returns to scale; all training variables equal to zero;

the costs in PLZ and costs in $€$ are the estimated costs to increase the outflow from unemployment by one person (at the mean);

the time effects are modelled by quarterly dummies.

Source: Polish Ministry of Labour and Social Policy; own calculations. 
Table 14: Augmented Matching Function Estimates with PLFS Data with Lagged Dependent Variables

\begin{tabular}{|c|c|c|c|c|c|c|c|c|}
\hline \multirow[t]{3}{*}{ Variable } & \multicolumn{4}{|c|}{ With current training expenditure } & \multicolumn{4}{|c|}{ Without current training expenditure } \\
\hline & \multicolumn{2}{|c|}{ Fixed effects } & \multicolumn{2}{|c|}{ Random effects } & \multicolumn{2}{|c|}{ Fixed effects } & \multicolumn{2}{|c|}{ Random effects } \\
\hline & Coeff. & $\mathrm{t}$-value & Coeff. & t-value & Coeff. & $\mathrm{t}$-value & Coeff. & t-value \\
\hline $\ln$ outflows (t-1) & -0.133 & -2.92 & 0.024 & 0.54 & -0.136 & -2.98 & 0.023 & 0.51 \\
\hline $\ln$ outflows (t-2) & -0.099 & -2.33 & 0.029 & 0.67 & -0.100 & -2.34 & 0.027 & 0.64 \\
\hline In outflows (t-3) & -0.050 & -1.17 & 0.066 & 1.56 & -0.048 & -1.13 & 0.065 & 1.53 \\
\hline $\ln$ outflows (t-4) & 0.023 & 0.53 & 0.124 & 2.88 & 0.026 & 0.60 & 0.124 & 2.90 \\
\hline In unemployment (t-1) & 0.282 & 1.63 & 0.486 & 4.25 & $0.299^{*}$ & 1.73 & 0.484 & 4.23 \\
\hline In vacancies (t-1) & $0.188^{*}$ & 1.94 & 0.159 & 2.73 & 0.196 & 2.02 & 0.153 & 2.64 \\
\hline Training expenditure & $-0.207^{*}$ & -1.69 & -0.127 & -1.14 & - & - & - & - \\
\hline Training exp. (t-1) & 0.131 & 1.15 & 0.137 & 1.21 & 0.058 & 0.55 & 0.061 & 0.66 \\
\hline Training exp.(t-2) & 0.028 & 0.27 & 0.026 & 0.25 & 0.036 & 0.35 & 0.013 & 0.13 \\
\hline Training exp.(t-3) & -0.116 & -1.18 & -0.065 & -0.72 & -0.075 & -0.78 & -0.065 & -0.73 \\
\hline IW expenditure & 0.010 & 0.15 & -0.011 & -0.23 & -0.009 & -0.14 & -0.014 & -0.31 \\
\hline PW expenditure & -0.084 & -1.42 & $-0.068^{*}$ & -1.69 & -0.090 & -1.52 & -0.063 & -1.58 \\
\hline Start-up loans exp. & 0.010 & 0.06 & 0.074 & 0.40 & 0.007 & 0.04 & 0.058 & 0.31 \\
\hline $\begin{array}{l}\text { Loans to enterprises } \\
\text { exp. }\end{array}$ & $0.242^{*}$ & 1.95 & 0.146 & 1.24 & 0.184 & 1.54 & 0.104 & 0.92 \\
\hline \multicolumn{9}{|c|}{ (fixed time effects omitted) } \\
\hline Constant & 1.648 & 2.32 & -0.298 & -0.76 & 1.529 & 2.16 & -0.289 & -0.74 \\
\hline $\mathrm{R}^{2}$ overall & \multicolumn{2}{|c|}{0.2289} & \multicolumn{2}{|c|}{0.4386} & \multicolumn{2}{|c|}{0.280} & \multicolumn{2}{|c|}{0.437} \\
\hline$N_{i}$ & \multicolumn{2}{|c|}{48} & \multicolumn{2}{|c|}{48} & \multicolumn{2}{|c|}{48} & \multicolumn{2}{|c|}{48.000} \\
\hline $\bar{N}_{t}$ & \multicolumn{2}{|c|}{11.15} & \multicolumn{2}{|c|}{10.64} & \multicolumn{2}{|c|}{11.15} & \multicolumn{2}{|c|}{10.64} \\
\hline F/LM test & \multicolumn{2}{|c|}{0.000} & \multicolumn{2}{|c|}{0.002} & \multicolumn{2}{|c|}{0.000} & \multicolumn{2}{|c|}{0.003} \\
\hline Hausman test & \multicolumn{2}{|c|}{-} & \multicolumn{2}{|c|}{0.000} & \multicolumn{2}{|c|}{-} & \multicolumn{2}{|c|}{0.000} \\
\hline CRS test & \multicolumn{2}{|c|}{0.000} & \multicolumn{2}{|c|}{0.136} & \multicolumn{2}{|c|}{0.000} & \multicolumn{2}{|c|}{0.095} \\
\hline Joint training test & & & & & & & & \\
\hline
\end{tabular}

Notes: shaded coefficients are significant at the 5 percent level; asterisked coefficients are significant at the 10 percent level; IW.: intervention works; PW.: public works; CRS: constant returns to scale; ' $\mathrm{R}^{2}$ overall' (as Stata calls it) is the correlation between the actual and the predicted outflows;

the null hypothesis of the F/LM test is the non-existence of voivodship-specific effects; test results are reported in terms of p-values, which means that the null hypothesis is rejected at the 5 percent significance level if the p-value is smaller than 0.05 ; the null hypotheses are non-existence of voivodship-specific effects; equality of random and fixed effects estimates; constant returns to scale; all training variables equal to zero;

the costs in PLZ and costs in $€$ are the estimated costs to increase the outflow from unemployment by one person; the time effects are modelled by quarterly dummies.

Source: Polish Ministry of Labour and Social Policy; own calculations. 
To sum up, there is some evidence that training programmes can reduce unemployment in the Polish labour market. However, this result is not very robust. It depends both on the analysed data set and the type of voivodship. Doubts on whether training programmes are of any use at all arise from the Polish Labour Force Survey data. Using this data source we find no effects of training expenditure on outflows to jobs. This is what has been argued in previous papers on Poland (Lehmann, 1995; Puhani and Steiner, 1996; 1997; Kwiatkowski and Tokarski, 1997).

Augmented matching functions for the whole of Poland on register data suggest that the cost of reducing unemployment by one person through training programmes lies between $€ 300$ to $€ 500$. Compared to the estimates of studies on the Czech and Slovak Republics, these figures seem rather low: Burda and Lubyova (1995), Svejnar, Terrell, and Münich (1995), and Boeri and Burda (1996) have estimated this cost to be between $€ 1,000$ and $€ 3,500$. In the previous literature on Poland no positive effects of training could be detected. By identifying positive effects from the register data, we differ from Lehmann (1995), Puhani and Steiner (1996; 1997), and Kwiatkowski and Tokarski (1997). Our analysis by region, however, shows that the positive training effects are mainly to be found in the industrialised voivodships, and perhaps also in the agricultural ones. It might be an encouraging result that training programmes are effective in those areas where the need to restructure the economy away from the old staple industries and low-tech agriculture is most urgent. These voivodships are not necessarily the ones with the highest unemployment rates, however. Classifying voivodships into three groups according to their unemployment rate shows no differences in the effects of training between low and high unemployment regions.

\subsection{Panel Evidence on the Effects of ALMP Programmes on the Outflows from Employment}

In this section, we investigate whether the Polish active labour market programmes have any effects on the outflows from employment to unemployment. On the one hand, ALMPs might encourage outflows from employment through displacement effects as mentioned in the Introduction: employers might want to sack workers who are employed without a subsidy in order to take on unemployed people whose wage is partly subsidised. Such displacement effects are therefore most likely to occur due to intervention works, public works, or loans to enterprises.

On the other hand, ALMPs might have a negative impact on outflows from employment to unemployment by preventing workers from being sacked in the first place. A priori consideration suggests that such effects may occur through training programmes, intervention and public works schemes, as well as loans to enterprises. Of course, displacement effects can overlap with the prevention of job losses. Hence 
we are at best able to identify the net result of these two effects with the data at hand.

In order to estimate the effects of ALMPs on the outflows from employment into unemployment, we use data from the PLFS on outflows from employment into unemployment as well as the stock of the employed in each voivodship. Summary statistics for the data have been presented in Table 2 in Section 4. Our model specification does not have a compelling theoretical basis as the matching function, but we use a comparable model regressing the outflows from employment into unemployment on the current and past stocks of employment, as well as expenditures on active labour market policies. As before, we also estimate the models with lagged dependent variables. Fixed and random effects models are estimated to control for any time-invariant unexplained heterogeneity between voivodships which cannot be explained otherwise with our data.

The estimation results are presented in Table 15 and Table 16. In all models, the specifications with lagged dependent variables show that their coefficients are significant. The Hausman tests of the orthogonality of the random effects to the regressors show that the random effects models are not rejected in the specification without lagged dependent variables. In the specifications with lagged dependent variables, though, the Hausman statistic always rejects the random effects model (as one may expect). The table also reports tests on the joint significance of the ALMP variables. If the effects are significant at the 10 percent level, the costs to prevent an additional outflow from employment into unemployment are calculated in Table 17. Positive numbers in Table 17 therefore mean that the ALMP programme in question prevents outflows from employment into unemployment. Negative numbers can be interpreted as evidence for displacement effects.

There is only evidence for displacement effects if current ALMP expenditure is included in the set of regressors. In these specifications, we find displacement effects for training and loans to enterprises. In the specification without lagged dependent variables, there is also weakly significant evidence for displacement effects in intervention works. But the sign of the effect changes when lagged dependent variables are included. In this case, there is also weakly significant evidence for displacement effects in public works. For training, it seems that an additional $€ 100$ spent on the programmes leads one more worker being displaced. If we just consider the rough size of the estimate and compare it with the estimates of the training effect on outflows from unemployment, we come to the conclusion that training just turns over the unemployment pool. However, this interpretation should not be taken too seriously, as we see that the displacement effect disappears completely if we strike out current training expenditure from our model. It is in fact quite probable that ALMP expenditures increase when more people lose their jobs. In this case, current ALMP expenditure is an endogenous variable and its coefficient 
is likely to be severely upward biased (i.e. the estimated cost in Table 17 is downward biased). This point applies to training as well as to public works and loans to enterprises. It is nevertheless interesting to observe that we have some weak evidence on displacement effects in loans for enterprises. However, these loans are tied to the precondition that the firm receiving the loan has not reduced its employment for the last 12 months. If there are displacement effects, then firms have found a way to circumvent the spirit of this programme by sacking some of their labour force a little later. Yet it should be stressed again that an alternative explanation for the finding of displacement effects is that the statistical results merely reflect endogeneity bias. This view is substantiated by the fact that no displacement effects can be discerned from the estimates without current ALMP expenditures.

We can draw firmer conclusions on start-up loans as programmes that can prevent unemployment from occurring in the first place. Why start-up loans should prevent outflows from employment may seem peculiar. An explanation can be that most people receiving loans quit their old jobs as employees and more or less directly become self-employed. As our data are collected quarterly, the period between job switches must be under 3 months to make this hypothesis consistent with the estimation results. Our estimates without current expenditure suggest that start-up loans are a rather cheap way to keep people off the dole. The estimated costs per person kept in employment range between $€ 100$ and $€ 130$. The estimated costs in the other (not preferred) specifications are even lower.

In sum, we do not interpret the results from this section as evidence in favour of displacement effects. The estimates which suggest such effects seem to be biased due to the endogeneity of ALMP expenditures. Instead, we have found that start-up loans can prevent people from becoming unemployed. The estimated costs to keep a person in employment through start-up loans lie between $€ 100$ and $€ 130$, which is very low. However, self-employment is only an option for the more capable amongst the unemployed and can therefore only be applied successfully on a small scale. 
Table 15: Estimation of Outflows from Employment without Lagged Dependent Variables

\begin{tabular}{|c|c|c|c|c|c|c|c|c|}
\hline \multirow[t]{3}{*}{ Variable } & \multicolumn{4}{|c|}{ With current ALMP expenditure } & \multicolumn{4}{|c|}{ Without current ALMP expenditure } \\
\hline & \multicolumn{2}{|c|}{ Fixed Effects } & \multicolumn{2}{|c|}{ Random Effects } & \multicolumn{2}{|c|}{ Fixed Effects } & \multicolumn{2}{|c|}{ Random Effects } \\
\hline & Coeff. & $\mathrm{t}$-value & Coeff. & t-value & Coeff. & t-value & Coeff. & t-value \\
\hline Employment & 2.041 & 3.69 & 1.664 & 3.47 & 1.514 & 2.89 & 1.276 & 2.77 \\
\hline Employment (t-1) & -2.163 & -3.52 & -2.313 & -3.79 & -1.633 & -2.73 & -1.764 & -3.04 \\
\hline Employment (t-2) & 1.904 & 2.91 & 1.595 & 2.57 & 1.566 & 2.48 & 1.404 & 2.35 \\
\hline Employment (t-3) & -0.813 & -1.25 & $-1.074^{*}$ & -1.67 & -0.880 & -1.38 & $-1.053^{*}$ & -1.69 \\
\hline Employment (t-4) & 0.869 & 1.58 & 0.715 & 1.37 & $0.879^{*}$ & 1.66 & 0.758 & 1.52 \\
\hline Training & 0.434 & 2.85 & 0.343 & 2.42 & - & - & - & - \\
\hline Training (t-1) & $-0.257^{*}$ & -1.68 & -0.348 & -2.40 & -0.135 & -1.02 & -0.176 & -1.54 \\
\hline Training (t-2) & 0.083 & 0.62 & 0.044 & 0.33 & 0.074 & 0.56 & 0.073 & 0.57 \\
\hline Training (t-3) & 0.095 & 0.67 & 0.043 & 0.31 & 0.024 & 0.18 & 0.010 & 0.08 \\
\hline Training (t-4) & 0.114 & 0.87 & 0.014 & 0.11 & 0.145 & 1.17 & 0.109 & 0.96 \\
\hline Intervention works & -0.217 & -2.40 & $-0.142^{*}$ & -1.70 & - & - & - & - \\
\hline Intervention works $(\mathrm{t}-1)$ & 0.052 & 0.53 & 0.077 & 0.78 & -0.043 & -0.52 & -0.004 & -0.05 \\
\hline Intervention works $(\mathrm{t}-2)$ & 0.155 & 1.50 & $0.195^{*}$ & 1.90 & 0.151 & 1.55 & $0.164^{*}$ & 1.72 \\
\hline Intervention works (t-3) & -0.090 & -0.85 & -0.077 & -0.73 & -0.119 & -1.18 & -0.107 & -1.08 \\
\hline Intervention works $(\mathrm{t}-4)$ & 0.069 & 0.75 & 0.056 & 0.62 & 0.021 & 0.23 & 0.035 & 0.40 \\
\hline Public works & 0.070 & 0.93 & 0.062 & 0.90 & - & - & - & - \\
\hline Public works (t-1) & 0.071 & 0.94 & 0.067 & 0.92 & 0.081 & 1.20 & 0.082 & 1.32 \\
\hline Public works (t-2) & 0.049 & 0.63 & 0.038 & 0.50 & 0.030 & 0.41 & 0.028 & 0.40 \\
\hline Public works (t-3) & 0.052 & 0.64 & 0.043 & 0.54 & 0.003 & 0.03 & 0.006 & 0.08 \\
\hline Public works (t-4) & -0.093 & -1.26 & -0.107 & -1.46 & -0.079 & -1.12 & -0.081 & -1.18 \\
\hline Start-up loans & -0.233 & -0.96 & -0.282 & -1.20 & - & - & - & - \\
\hline Start-up loans (t-1) & 0.167 & 0.97 & 0.162 & 0.96 & 0.118 & 0.80 & 0.124 & 0.88 \\
\hline Start-up loans (t-2) & -0.449 & -2.81 & -0.489 & -3.14 & -0.484 & -3.12 & -0.480 & -3.19 \\
\hline Start-up loans (t-3) & -0.009 & -0.06 & -0.061 & -0.39 & 0.009 & 0.06 & 0.013 & 0.09 \\
\hline Start-up loans (t-4) & -0.218 & -1.37 & -0.233 & -1.52 & -0.049 & -0.33 & -0.068 & -0.47 \\
\hline
\end{tabular}

(continued on the next page) 
Table 15: Estimation of Outflows from Employment without Lagged Dependent Variables (ctd.)

\begin{tabular}{|c|c|c|c|c|c|c|c|c|}
\hline \multirow[t]{3}{*}{ Variable } & \multicolumn{4}{|c|}{ With current ALMP expenditure } & \multicolumn{4}{|c|}{ Without current ALMP expenditure } \\
\hline & \multicolumn{2}{|c|}{ Fixed effects } & \multicolumn{2}{|c|}{ Random effects } & \multicolumn{2}{|c|}{ Fixed effects } & \multicolumn{2}{|c|}{ Random effects } \\
\hline & Coeff. & t-value & Coeff. & t-value & Coeff. & t-value & Coeff. & t-value \\
\hline Loans to enterprises & 0.343 & 2.17 & 0.366 & 2.49 & - & - & - & - \\
\hline Loans to enterprises $(\mathrm{t}-1)$ & 0.129 & 0.89 & 0.140 & 1.03 & 0.170 & 1.21 & $0.230^{*}$ & 1.78 \\
\hline Loans to enterprises $(\mathrm{t}-2)$ & 0.021 & 0.15 & 0.000 & 0.00 & -0.005 & -0.04 & 0.021 & 0.16 \\
\hline Loans to enterprises $(\mathrm{t}-3)$ & -0.063 & -0.47 & -0.097 & -0.74 & -0.018 & -0.14 & -0.019 & -0.14 \\
\hline Loans to enterprises ( $\mathrm{t}-4)$ & -0.203 & -1.49 & $-0.216^{*}$ & -1.66 & -0.132 & -1.03 & -0.127 & -1.02 \\
\hline \multicolumn{9}{|c|}{ (fixed time effects omitted) } \\
\hline Constant & -9.152 & -2.05 & -1.748 & -3.55 & $-7.000^{*}$ & -1.66 & -2.273 & -3.83 \\
\hline $\mathrm{R}^{2}$ overall & \multicolumn{2}{|c|}{0.271} & \multicolumn{2}{|c|}{0.361} & \multicolumn{2}{|c|}{0.270} & \multicolumn{2}{|c|}{0.330} \\
\hline$N_{i}$ & \multicolumn{2}{|c|}{49} & \multicolumn{2}{|c|}{49} & \multicolumn{2}{|c|}{49} & \multicolumn{2}{|c|}{49} \\
\hline $\bar{N}_{t}$ & \multicolumn{2}{|c|}{11.41} & \multicolumn{2}{|c|}{11.31} & \multicolumn{2}{|c|}{12.35} & \multicolumn{2}{|c|}{12.23} \\
\hline F/LM test & \multicolumn{2}{|c|}{0.000} & \multicolumn{2}{|c|}{0.000} & \multicolumn{2}{|c|}{0.000} & \multicolumn{2}{|c|}{0.000} \\
\hline Hausman test & \multicolumn{2}{|c|}{-} & \multicolumn{2}{|c|}{0.999} & \multicolumn{2}{|c|}{-} & \multicolumn{2}{|c|}{1.000} \\
\hline Joint test on training & \multicolumn{2}{|c|}{0.033} & \multicolumn{2}{|c|}{0.120} & \multicolumn{2}{|c|}{0.380} & \multicolumn{2}{|c|}{0.405} \\
\hline Joint test on IW & \multicolumn{2}{|c|}{0.130} & \multicolumn{2}{|c|}{0.075} & \multicolumn{2}{|c|}{0.602} & & \\
\hline Joint test on PW & & & & & & & & \\
\hline $\begin{array}{l}\text { Joint test on start-up } \\
\text { loans }\end{array}$ & & & & & & & & \\
\hline Joint test on loans to ent. & & & & & & & & \\
\hline
\end{tabular}

Notes: shaded coefficients are significant at the 5 percent level; asterisked coefficients are significant at the 10 percent level;

IW: intervention works; PW: public works; ent.: enterprises;

' $\mathrm{R}^{2}$ overall' (as Stata calls it) is the correlation between the actual and the predicted outflows;

the null hypothesis of the F/LM test is the non-existence of voivodship-specific effects; test results are reported in terms of p-values, which means that the null hypothesis is rejected at the 5 percent significance level if the p-value is smaller than 0.05 ;

the null hypotheses are non-existence of voivodship-specific effects; equality of random and fixed effects estimates; all training etc. variables equal to zero;

the time effects are modelled by quarterly dummies.

Sources: PLFS; Polish Ministry of Labour and Social Policy; own calculations. 
Table 16: Estimation of Outflows from Employment with Lagged Dependent Variables

\begin{tabular}{|c|c|c|c|c|c|c|c|c|}
\hline \multirow[t]{3}{*}{ Variable } & \multicolumn{4}{|c|}{ With current ALMP expenditure } & \multicolumn{4}{|c|}{ Without current ALMP expenditure } \\
\hline & \multicolumn{2}{|c|}{ Fixed effects } & \multicolumn{2}{|c|}{ Random effects } & \multicolumn{2}{|c|}{ Fixed effects } & \multicolumn{2}{|c|}{ Random effects } \\
\hline & Coeff. & t-value & Coeff. & t-value & Coeff. & t-value & Coeff. & t-value \\
\hline Outflows from empl. (t-1) & -0.103 & -2.11 & 0.114 & 2.48 & -0.104 & -2.17 & 0.107 & 2.36 \\
\hline Outflows from empl. (t-2) & -0.211 & -4.39 & -0.045 & -0.96 & -0.218 & -4.66 & -0.040 & -0.88 \\
\hline Outflows from empl. (t-3) & -0.055 & -1.14 & $0.088^{*}$ & 1.87 & -0.063 & -1.33 & 0.109 & 2.39 \\
\hline Outflows from empl. (t-4) & -0.040 & -0.80 & 0.112 & 2.38 & -0.047 & -0.99 & 0.113 & 2.49 \\
\hline Employment & 2.378 & 3.87 & 2.042 & 3.74 & 1.737 & 2.93 & 1.599 & 2.98 \\
\hline Employment (t-1) & -2.503 & -3.63 & -3.130 & -4.34 & -1.862 & -2.75 & -2.465 & -3.49 \\
\hline Employment (t-2) & 2.619 & 3.54 & 2.568 & 3.44 & 2.293 & 3.16 & 2.328 & 3.16 \\
\hline Employment (t-3) & $-1.327^{*}$ & -1.82 & -1.718 & -2.25 & $-1.302^{*}$ & -1.80 & -1.747 & -2.31 \\
\hline Employment (t-4) & 0.818 & 1.34 & 0.618 & 1.05 & 0.906 & 1.54 & 0.673 & 1.17 \\
\hline Training & 0.411 & 2.67 & 0.339 & 2.28 & - & - & - & - \\
\hline Training (t-1) & -0.180 & -1.16 & -0.321 & -2.09 & -0.068 & -0.51 & -0.156 & -1.34 \\
\hline Training (t-2) & 0.148 & 1.08 & 0.077 & 0.54 & 0.125 & 0.92 & 0.128 & 0.91 \\
\hline Training (t-3) & 0.052 & 0.37 & -0.009 & -0.06 & 0.004 & 0.03 & -0.056 & -0.39 \\
\hline Training (t-4) & 0.161 & 1.24 & 0.006 & 0.05 & 0.179 & 1.45 & 0.096 & 0.82 \\
\hline Intervention works & -0.222 & -2.41 & $-0.151^{*}$ & -1.75 & - & - & - & - \\
\hline Intervention works $(\mathrm{t}-1)$ & 0.039 & 0.39 & 0.093 & 0.89 & -0.050 & -0.58 & 0.030 & 0.37 \\
\hline Intervention works $(\mathrm{t}-2)$ & 0.153 & 1.46 & $0.199^{*}$ & 1.82 & 0.130 & 1.30 & 0.150 & 1.44 \\
\hline Intervention works $(\mathrm{t}-3)$ & -0.117 & -1.09 & -0.097 & -0.86 & -0.150 & -1.45 & -0.123 & -1.13 \\
\hline Intervention works $(\mathrm{t}-4)$ & 0.107 & 1.12 & 0.082 & 0.83 & 0.062 & 0.67 & 0.060 & 0.63 \\
\hline Public works & 0.063 & 0.83 & 0.053 & 0.75 & - & - & - & - \\
\hline Public works (t-1) & 0.100 & 1.34 & 0.079 & 1.02 & $0.112^{*}$ & 1.64 & 0.087 & 1.36 \\
\hline Public works (t-2) & 0.077 & 0.98 & 0.025 & 0.31 & 0.058 & 0.78 & 0.021 & 0.27 \\
\hline Public works (t-3) & 0.088 & 1.08 & 0.039 & 0.46 & 0.042 & 0.53 & 0.001 & 0.02 \\
\hline Public works (t-4) & -0.077 & -1.02 & $-0.128^{*}$ & -1.64 & -0.060 & -0.83 & -0.097 & -1.30 \\
\hline Start-up loans & -0.256 & -1.04 & -0.319 & -1.31 & - & - & - & - \\
\hline Start-up loans (t-1) & 0.205 & 1.19 & 0.194 & 1.10 & 0.149 & 1.01 & 0.122 & 0.83 \\
\hline Start-up loans (t-2) & -0.471 & -2.93 & -0.543 & -3.31 & -0.502 & -3.20 & -0.554 & -3.41 \\
\hline Start-up loans (t-3) & -0.006 & -0.04 & -0.023 & -0.14 & -0.005 & -0.03 & 0.054 & 0.33 \\
\hline Start-up loans (t-4) & $-0.290^{*}$ & -1.78 & -0.202 & -1.24 & -0.105 & -0.68 & -0.056 & -0.36 \\
\hline
\end{tabular}


Table 16: Estimation of Outflows from Employment with Lagged Dependent Variables (ctd.)

\begin{tabular}{|c|c|c|c|c|c|c|c|c|}
\hline \multirow[t]{3}{*}{ Variable } & \multicolumn{4}{|c|}{ With current ALMP expenditure } & \multicolumn{4}{|c|}{ Without current ALMP expenditure } \\
\hline & \multicolumn{2}{|c|}{ Fixed effects } & \multicolumn{2}{|c|}{ Random effects } & \multicolumn{2}{|c|}{ Fixed effects } & \multicolumn{2}{|c|}{ Random effects } \\
\hline & Coeff. & t-value & Coeff. & t-value & Coeff. & t-value & Coeff. & t-value \\
\hline Loans to enterprises & 0.376 & 2.41 & 0.357 & 2.35 & - & - & - & - \\
\hline Loans to enterprises ( $\mathrm{t}-1)$ & 0.177 & 1.22 & 0.116 & 0.83 & 0.201 & 1.44 & $0.221^{*}$ & 1.67 \\
\hline Loans to enterprises ( $\mathrm{t}-2)$ & 0.072 & 0.52 & 0.004 & 0.03 & 0.067 & 0.50 & 0.029 & 0.21 \\
\hline Loans to enterprises ( $\mathrm{t}-3$ ) & -0.050 & -0.37 & -0.130 & -0.94 & -0.002 & -0.01 & -0.073 & -0.54 \\
\hline Loans to enterprises ( $\mathrm{t}-4)$ & -0.181 & -1.33 & -0.210 & -1.56 & -0.105 & -0.82 & -0.132 & -1.00 \\
\hline \multicolumn{9}{|c|}{ (fixed time effects omitted) } \\
\hline Constant & $-9.371^{*}$ & -1.83 & -1.104 & -2.56 & -8.356 & -1.72 & -1.387 & -3.18 \\
\hline $\mathrm{R}^{2}$ overall & \multicolumn{2}{|c|}{0.235} & \multicolumn{2}{|c|}{0.383} & \multicolumn{2}{|c|}{0.221} & \multicolumn{2}{|c|}{0.349} \\
\hline$N_{i}$ & \multicolumn{2}{|c|}{47} & \multicolumn{2}{|c|}{47} & \multicolumn{2}{|c|}{48} & \multicolumn{2}{|c|}{48} \\
\hline $\bar{N}_{t}$ & \multicolumn{2}{|c|}{10.32} & \multicolumn{2}{|c|}{9.10} & \multicolumn{2}{|c|}{10.94} & \multicolumn{2}{|c|}{8.25} \\
\hline F/LM test & \multicolumn{2}{|c|}{0.000} & \multicolumn{2}{|c|}{0.259} & \multicolumn{2}{|c|}{0.000} & \multicolumn{2}{|c|}{0.101} \\
\hline Hausman test & \multicolumn{2}{|c|}{-} & \multicolumn{2}{|c|}{0.000} & \multicolumn{2}{|c|}{-} & \multicolumn{2}{|c|}{0.000} \\
\hline Joint test on training & \multicolumn{2}{|c|}{0.029} & \multicolumn{2}{|c|}{0.206} & \multicolumn{2}{|c|}{0.335} & \multicolumn{2}{|c|}{0.622} \\
\hline Joint test on IW & \multicolumn{2}{|c|}{0.108} & \multicolumn{2}{|c|}{0.038} & \multicolumn{2}{|c|}{0.586} & & \\
\hline Joint test on PW & & & & & & & & \\
\hline $\begin{array}{l}\text { Joint test on start-up } \\
\text { loans }\end{array}$ & & & & & & & & \\
\hline Joint test on loans to ent. & & & & & & & & \\
\hline
\end{tabular}

Notes: shaded coefficients are significant at the 5 percent level; asterisked coefficients are significant at the 10 percent level;

empl.: employment; IW: intervention works; PW: public works; ent.: enterprises;

' $\mathrm{R}^{2}$ overall' (as Stata calls it) is the correlation between the actual and the predicted outflows;

the null hypothesis of the F/LM test is the non-existence of voivodship-specific effects; test results are reported in terms of p-values, which means that the null hypothesis is rejected at the 5 percent significance level if the p-value is smaller than 0.05 ;

the null hypotheses are non-existence of voivodship-specific effects; equality of random and fixed effects estimates; all training etc. variables equal to zero;

the time effects are modelled by quarterly dummies.

Sources: PLFS; Polish Ministry of Labour and Social Policy; own calculations. 
Table 17: Estimated Costs in Euro to Keep a Person Employed through ALMPs

\begin{tabular}{l|c|c|c|c|c}
\hline \hline ALMP programme & \multicolumn{3}{|c}{ Without lagged dependent variables } \\
& \multicolumn{2}{|c|}{$\begin{array}{c}\text { With current ALMP } \\
\text { expenditure }\end{array}$} & \multicolumn{2}{|c}{$\begin{array}{c}\text { Without current } \\
\text { ALMP expenditure }\end{array}$} \\
& $\begin{array}{c}\text { Fixed } \\
\text { effects }\end{array}$ & $\begin{array}{l}\text { Random } \\
\text { effects }\end{array}$ & $\begin{array}{c}\text { Fixed } \\
\text { effects }\end{array}$ & $\begin{array}{c}\text { Random } \\
\text { effects }\end{array}$ \\
\hline Training & -91 & $\mathbf{- 4 4 4}$ & - & - \\
Intervention works & $(1388)$ & $\mathbf{- 3 9 2 *}$ & - & - \\
Public works & - & - & - & - \\
Start-up loans & $57^{*}$ & $\mathbf{4 7}$ & 105 & $\mathbf{1 0 4}$ \\
Loans to enterprises & - & $\mathbf{- 2 2 1}$ & - & - \\
\hline & \multicolumn{2}{|c|}{ With lagged dependent variables } \\
Training & $\mathbf{- 1 0 1}$ & - & - & - \\
Intervention works & $\mathbf{1 4 6 0}$ & -249 & - & -257 \\
Public works & $\mathbf{- 2 3 8 *}$ & - & - & - \\
Start-up loans & $\mathbf{7 3}$ & 35 & $\mathbf{1 3 2}$ & 70 \\
Loans to enterprises & $\mathbf{- 1 5 2 *}$ & $-227^{*}$ & - & - \\
\hline \hline
\end{tabular}

Notes: Numbers with an asterisk are only significant at the 10 percent level. Numbers in brackets are just about not significant at the 10 percent level; numbers without brackets and asterisks are significant at the 5 percent level; if a number is negative, it might be interpreted as evidence in favour of displacement effects; the bold numbers indicate the preferred models (fixed or random effects) as indicated by the Hausman test; we generally prefer the models without current ALMP expenditure $\left(4^{\text {th }}\right.$ and $5^{\text {th }}$ columns $)$ because they are less likely to be affected by endogeneity bias.

Sources: PLFS; Polish Ministry of Labour and Social Policy; own calculations.

\section{Conclusions}

We have analysed the Polish active labour market programmes from a macroeconomic point of view. We estimated the effects of training programmes on the outflows from unemployment and the effects of all ALMP programmes on the outflows from employment. The variety of specifications we presented has been revealing. In contrast to other studies on Poland, we have shown that it can make a difference to the estimates whether current ALMP expenditure is excluded from the set of regressors to reduce the endogeneity problem, whether lagged dependent variables are included to take account of the dynamics, and whether fixed or random effects models are estimated.

The empirical evidence from both the time-series as well as the panel data gives some tentative support to the view that public training programmes can be used to reduce unemployment. In the specifications where significant effects of training programmes can be detected, the average cost to reduce unemployment by one 
person in Poland through training programmes lies between $€ 200$ and $€ 500$. That these costs are comparatively low in relation to the estimates for the Czech and Slovak Republic (between $€ 1,000$ and $€ 3,000$ ) speaks in favour of the Polish training programmes. Our regional analysis has shown that the costs to reduce unemployment through training are higher in the industrial voivodships (between $€$ 500 and $€ 900$ ), than in the agricultural ones (around $€ 100$ ). No effects of training could be detected in the modern voivodships. The persistent and large differences in the development of Polish regions ( $c f$. Kwiatkowski and Kubiak, 1998) may cause social and economic challenges in the future which may go beyond the Polish borders by way of emigration to western Europe (cf. Zimmermann, 1993). If this tentative evidence on the regional effectiveness of public training can be given any credence, training policies may be used to support a more equal development of Polish regions.

However, it has to be stressed that positive training effects can only be found when using register data. All model specifications that use Polish labour force survey (PLFS) data suggest that training has no effect on the outflows from unemployment. One explanation of the sensitivity of the estimates with respect to the data set can be the imprecision with which outflows from unemployment are measured in some voivodships in the PLFS. Another explanation can be the different definitions of unemployment in the two data sets. The register unemployment data may include less long-term unemployed people than the PLFS data, because they might drop off the register after unemployment benefits run out. Our estimates of the coefficients on the unemployment stock in the matching functions are consistent with this hypothesis, which leads to the conclusion that training works better for the more able amongst the unemployed (as positive training effects are only found with the register data). This is unsurprising as training requires the ability to acquire new knowledge.

To test whether ALMP programmes have any displacement effects, or whether they can prevent unemployment to occur in the first place, we have estimated the effects of the programmes on the outflows from employment into unemployment. We have found no convincing evidence on displacement effects. However, start-up loans seem to be able to keep down the number of people who join the dole queue. Nevertheless, those people who dare to take out a loan in order to run their own business are only a small group and so the small costs estimated to keep a person in employment through start-up loans (between $€ 100$ and $€ 130$ ) should not be interpreted as safe evidence that an expansion of start-up loans would be successful. In addition, more empirical evidence would be required on start-up loans, especially on the type and length of self-employment, before any firm statements should be made. 


\section{References}

Ahn, S.C. and P. Schmidt (1995): Efficient Estimation of Models for Dynamic Panel Data, Journal of Econometrics 68: 5-27.

Baltagi, B.H. (1995): Econometric Analysis of Panel Data, Chichester: John Wiley $\&$ Sons.

Blanchard, O.J. and P. Diamond (1989): The Beveridge Curve, Brookings Papers on Economic Activity 1: 1-60.

Blanchard O.J., and P. Diamond (1990): The Aggregate Matching Function, in: Diamond, P. (ed.): Growth, Productivity, Unemployment, Essays to Celebrate Bob Solow's Birthday, 159-201, Cambridge MA: MIT Press.

Boeri, T. (1994a): Transitional Unemployment, Economics of Transition 2: 1-26

Boeri, T. (1994b): Labour Market Flows and the Persistence of Unemployment in Central and Eastern Europe, in: OECD (ed.): Unemployment in Transition Countries: Transient or Persistent?, 13-56, Paris: OECD.

Boeri, T. (1996): Unemployment Outflows and the Scope of Labour Market Policies in Central and Eastern Europe, in: OECD (ed.): Lessons from Labour Market Policies in Transition Countries, 41-70, Paris: OECD.

Boeri, T. and M.C. Burda (1996): Active Labor Market Policies, Job Matching and the Czech Miracle, European Economic Review 40: 805-817.

Boeri, T. and S. Scarpetta (1995): Emerging Regional Labour Market Dynamics in Central and Eastern Europe, in: OECD (ed.): The Regional Dimension of Unemployment in Transition Economies, A Challenge for Labour Market and Social Policies, 75-87, Paris: OECD.

Burda, M. (1993): Labour Markets in Eastern Europe. Economic Policy 16: 101137.

Burda, M. and M. Lubyova (1995): The Impact of Active Labour Market Policies: A Closer Look at the Czech and Slovak Republics, in: Newberry, D. (ed.): Tax and Benefit Reform in Central and Eastern Europe, 173-205, London: CEPR, also: CEPR Discussion paper No.1102, London.

Burda, M. and S. Profit (1996): Matching Across Space: Evidence on Mobility in the Czech Republic, Labour Economics 3: 255-278.

Burda, M. and C. Wyplosz (1994): Gross Worker and Job Flows in Europe, European Economic Review 38: 1287-1315.

Deutsche Bundesbank (1992): Statistische Beihefte zu den Monatsberichten der Deutschen Bundesbank 1992(4), Reihe 5: Die Währungen der Welt, Frankfurt / Main. 
Disney, R. et al. (1992): Helping the Unemployed, Active Labour Market Policies in Britain and Germany, Worcester: Billing \& Sons.

Entorf, H. (1995): Mismatch-Arbeitslosigkeit in Deutschland: Eine Kritik bestehender Meßkonzepte und neue Evidenz, in: Steiner, V. and L. Bellman (eds.): Mikroökonomik des Arbeitsmarktes, Beiträge zur Arbeitsmarkt und Berufsforschung, Nuremberg.

Franz, W. (1995): Central and East European Labour Markets in Transition: Developments, Causes, and Cures, CEPR Discussion Paper No.1132, London.

Franz, W. (1996): Arbeitsmarktökonomik, $3^{\text {rd }}$ edition, Berlin: Springer.

Góra, M., H. Lehmann, M. Socha and U. Sztanderska (1996): Labour Market Policies in Poland, in: OECD (ed.): Lessons from Labour Market Policies in Transition Countries, 151-176, Paris: OECD.

Greene, W.H. (1997): Econometric Analysis, $3^{\text {rd }}$ edition, New York: Macmillan.

Haskel, J. and R. Jackman (1988): Long-Term Unemployment in Britain and the Effects of the Community Programme, Oxford Bulletin of Economics and Statistics 50: 379-408.

Hausman, J.A. (1978): Specification Tests in Econometrics, Econometrica 46: 12511271.

Kalaska, M. and J. Witkowski (1997): Labour Market in Poland in 1996: Continuation of Positive Trends. Statistical Studies and Trends, Central Statistical Office, Department of Labour Statistics, Warsaw.

Kiviet, J.F. (1995): On bias, inconsistency, and efficiency of various estimators in dynamic panel data models, Journal of Econometrics 68: 53-78.

Kwiatkowski, E. and B. Gawronska (1995): Variation of Regional Unemployment and Regional Employment Structure in Poland, Institute of Economics, University of Lodz, mimeo.

Kwiatkowski, E. and T. Tokarski (1997): Active Labour Market Policies in Poland, An Augmented Matching Function Approach, Institute of Economics, University of Lodz, mimeo.

Kwiatkowski, E. and P. Kubiak (1998): On Some Determinants of Regional Unemployment in Poland in Transition, Institute of Economics, University of Lodz, mimeo.

Layard, R., S. Nickell and R. Jackman (1991): Unemployment: Macroeconomic Performance and the Labour Market, Oxford: Alden Press.

Lehmann, H. (1995): Active Labor Market Policies in the OECD and in Selected Transition Economies, World Bank Policy Research Working Paper No.1502, Washington D.C. 
Lenkova, C. (1997): Persistently High Unemployment throughout the Transition What is the Reason? (The Bulgarian Case), CERGE and IHS, Prague and Vienna, mimeo.

McCloskey, D.N. and S.T. Ziliak (1996): The Standard Error of Regressions, Journal of Economic Literature 34: 97-114.

Pissarides, C.A. (1990): Equilibrium Unemployment Theory, Cambridge, MA: Basil Blackwell.

Puhani, P.A. and V. Steiner (1996): Public Works for Poland? Active Labour Market Policies During Transition, ZEW Discussion Paper No. 96-01, Mannheim.

Puhani, P.A. and V. Steiner (1997): The Effectiveness and Efficiency of Active Labour Market Programmes in Poland, Empirica 24: 209-231.

Steiner, V. and E. Kwiatkowski (1995): The Polish Labour Market in Transition, ZEW Discussion Paper No.95-03, Mannheim.

Steiner, V. et al. (1998): Strukturanalyse der Arbeitsmarktentwicklung in den neuen Bundesländern, Endbericht für das Bundesministerium für Wirtschaft, Zentrum für Europäische Wirtschaftsforschung and Rheinisch-Westfälisches Institut für Wirtschaftsforschung, Mannheim and Essen.

Svejnar, J., K. Terrell and D. Münich (1995): Unemployment in the Czech and Slovak Republics, in: Svejnar, J. (ed.): The Czech Republic and Economic Transition in Eastern Europe, 285-316, San Diego, CA: Academic Press.

Szarkowski, A. and J. Witkowski (1994): The Polish Labour Force Survey, Statistics in Transition, Journal of the Polish Statistical Association 1: 467-483.

Zimmermann, K.F. (1993): Industrial Restructuring, Unemployment and Migration, in: L. Bekemans and L. Tsoukalis (eds.): Europe and Global Economic Interdependence, 25-52, European Interuniversity Press. 


\section{Appendix}

\section{Figure 3: $\quad$ The Voivodships of Poland - Map, Codes and Names}

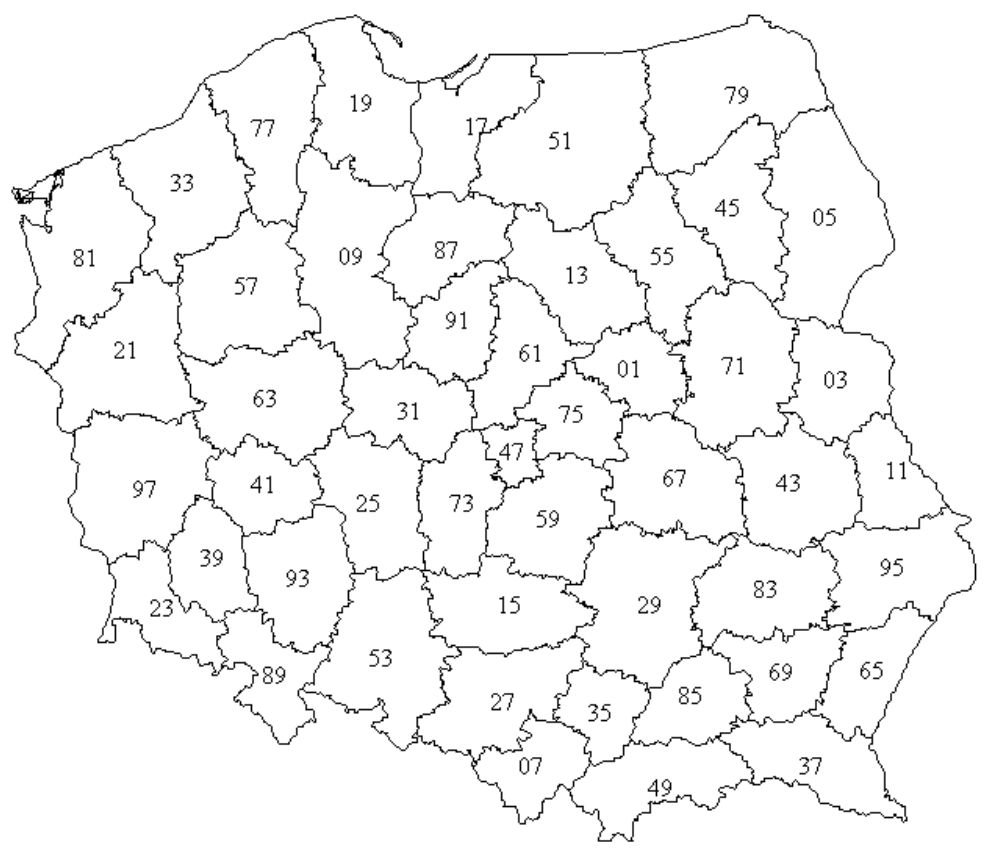

\begin{tabular}{c|c||c|c||c|c}
\hline \hline Code & Name & Code & Name & Code & Name \\
\hline 1 & Stoleczne Warszawskie & 35 & Krakowskie & 69 & Rzeszowskie \\
3 & Bialskopodlaskie & 37 & Krosnienskie & 71 & Siedleckie \\
5 & Bialostockie & 39 & Legnickie & 73 & Sieradzkie \\
7 & Bielskie & 41 & Leszczynskie & 75 & Skierniewickie \\
9 & Bydgoskie & 43 & Lubelskie & 77 & Slupskie \\
11 & Chelmskie & 45 & Lomzynskie & 79 & Suwalskie \\
13 & Ciechanowskie & 47 & Lodzkie & 81 & Szczecinskie \\
15 & Czestochowskie & 49 & Nowosadeckie & 83 & Tarnobrzeskie \\
17 & Elblaskie & 51 & Olsztynskie & 85 & Tarnowskie \\
19 & Gdanskie & 53 & Opolskie & 87 & Torunskie \\
21 & Gorzowskie & 55 & Ostroleckie & 89 & Walbrzyskie \\
23 & Jeleniogorskie & 57 & Pilskie & 91 & Wloclawskie \\
25 & Kaliskie & 59 & Piotrkowskie & 93 & Wroclawskie \\
27 & Katowickie & 61 & Plockie & 95 & Zamojskie \\
29 & Kieleckie & 63 & Poznanskie & 97 & Zielonogorskie \\
31 & Koninskie & 65 & Przemyskie & - & - \\
33 & Koszalinskie & 67 & Radomskie & - & - \\
\hline \hline
\end{tabular}

Note: The voivodship codes are the standard codes used by the Polish Central Statistical Office (GUS).

Source: Puhani and Steiner (1996); RegioGraph 2.0 software. 
Figure 4: $\quad$ Unemployment Across Polish Voivodships

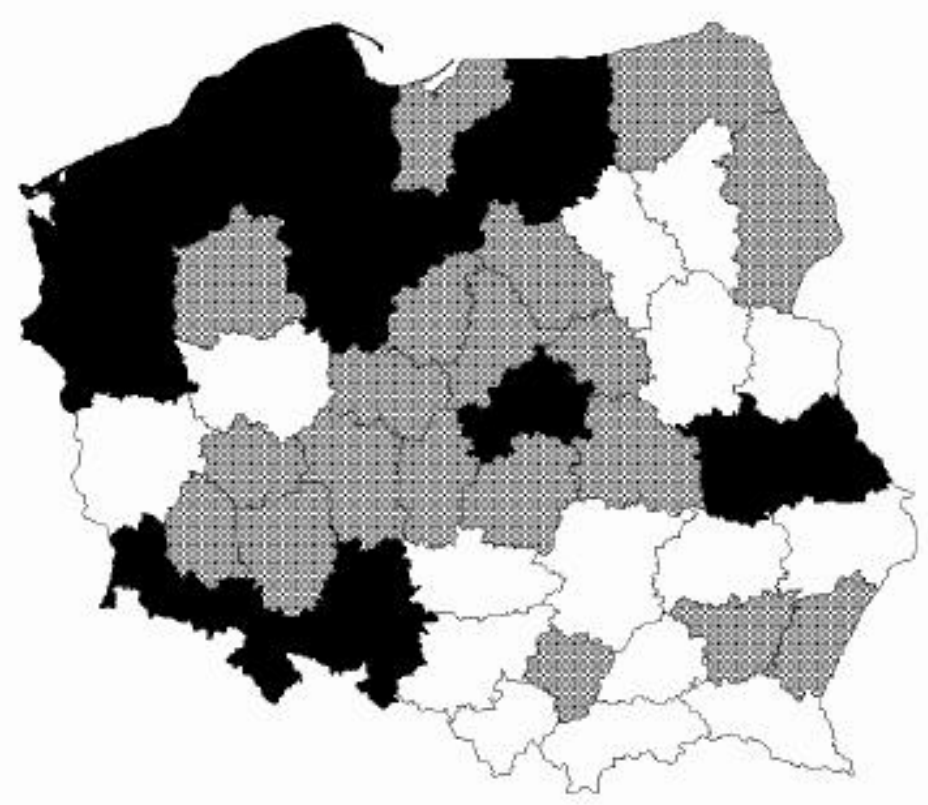

Notes: The black-(white-) shaded areas are the 15 voivodships with the highest (lowest) unemployment rates. The 19 hatched voivodships have unemployment rates between those two groups.

Source: Polish Labour Force Survey May 1992; own calculations.

Figure 5: Modern, Industrial, and Agricultural Voivodships

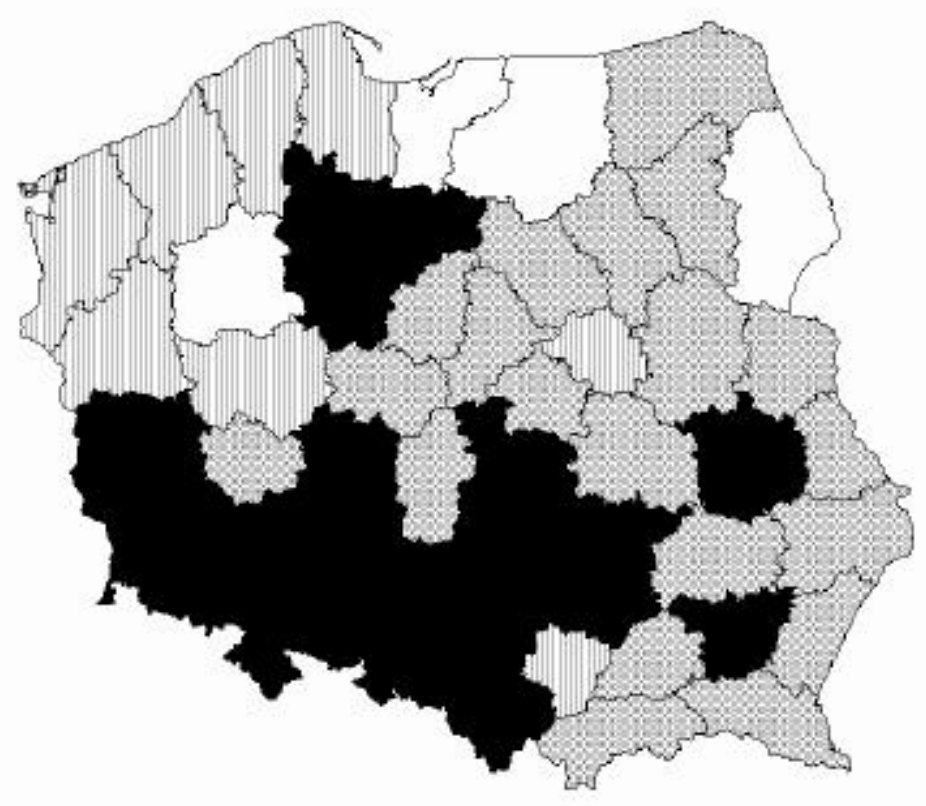

Notes: The striped voivodships are modern, the black ones industrial, the patterned ones agricultural, and the white ones belong to none of these categories.

Source: Kwiatkowski and Gawronska (1995). 